
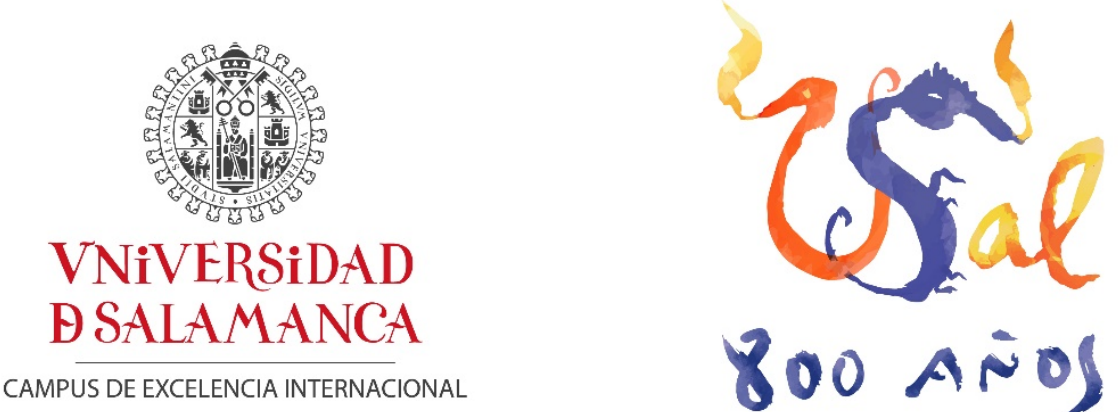

CAMPUS DE EXCELENCIA INTERNACIONAL

800 Añol

1218 - 2018

ESCUELA DE DOCTORADO ‘STUDII SALAMANTINI’

Programa de Doctorado

Estado de Derecho y gobernanza global

\author{
TESIS DOCTORAL
}

\title{
El control parlamentario a través de las comisiones investigadoras y la corrupción política
}

\section{VIVIANA CAICEDO ZAPATA}

Directores:

Nicolás RODRÍGUEZ-GARCÍA

Mario HERNÁNDEZ RAMOS

Ana E. CARRILLO DEL TESO 

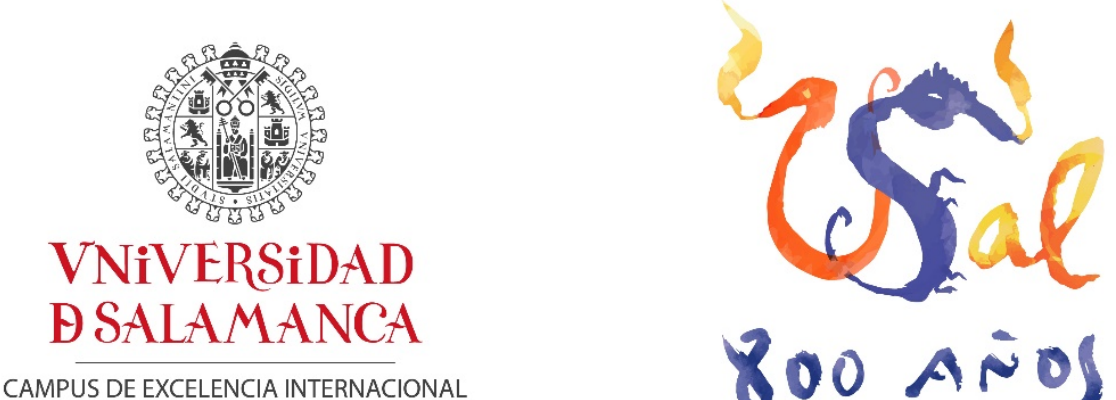

CAMPUS DE EXCELENCIA INTERNACIONAL

800 Años

$1218-2018$

ESCUELA DE DOCTORADO ‘STUDII SALAMANTINI’

Programa de Doctorado

Estado de Derecho y gobernanza global

TESIS DOCTORAL

\section{El control parlamentario a través de las comisiones investigadoras y la corrupción política}

\section{VIVIANA CAICEDO ZAPATA}

Tesis Doctoral presentada para obtener el grado de Doctor por la Universidad de Salamanca (España), dirigida por Nicolás RODRÍGUEZ-GARCÍA (Catedrático de Derecho Procesal Universidad de Salamanca), Mario HERNÁNDEZ RAMOS (Profesor Titular de Derecho Constitucional Universidad de Salamanca) y Ana E. CARRILLO DEL TESO (Profesora Ayudante Doctor de Derecho Procesal Universidad de Salamanca). 


\section{EL CONTROL PARLAMENTARIO A TRAVÉS DE LAS COMISIONES \\ INVESTIGADORAS Y LA CORRUPCIÓN POLÍTICA}

\section{ÍNDICE}

INTRODUCCIÓN.

PARTE I: ALGUNOS ANTECEDENTES HISTÓRICOS DE LA CORRUPCIÓN.

Capítulo I - Alcances históricos de la corrupción y su tradición en el tiempo.... 16

1- Rastros documentados de corrupción en... la Edad Antigua.................. 17

$1.1 \quad$ Registros de corrupción antes de Cristo............................. 17

1.2 Develaciones de corrupción después de Cristo ........................ 20

2- $\quad$ Memorias de un juicio por corrupción en el año 399 antes de Cristo....... 22

$2.1 \quad$ Acusación y defensa de Sócrates ................................. 23

2.1.1 Acusación.................................................. 23

2.1.2 Defensa socrática............................................ 25

2.2 Enseñanzas historiográficas de un procesado por apología de la corrupción.................................................. 27

3- La histórica legalidad de la venta de cargos públicos como tradición en la Europa medieval........................................... 28

2.1 La Simonía y El Nicolaísmo..................................... 29

Capítulo II - Memorias de la colonización de la corrupción en el Virreinato del Perú.................................................................................. 32

$1 \quad$ Crónicas de las memorias españolas............................... 34

$1.1 \quad$ Algunos datos del memorial de Juan de Aponte Figueroa.................. 34

1.2 Las noticias secretas de América detalles no revelados de Antonio de Ulloa y Jorge Juan......................................... 35

2 Reseñas virreinales del periodo de la corrupción colonial peruana......... 40

2.1 Francisco Borja y Aragón, Príncipe de Esquilache (1615-1621)........ 40

2.2 El Marqués de Castelldosrius Manuel de Oms de Santpau OlimSentemenat i de Lanuza (1704-1709)........................... 42

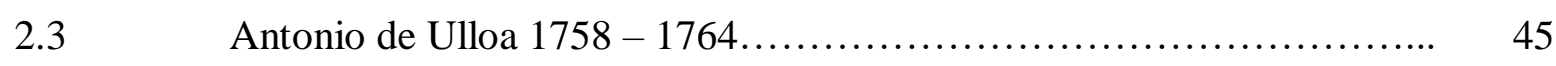

Capítulo III - Efectos de la corrupción en el Perú republicano ................. 48 
1- Herencia ancestral aplicada en el Perú independiente.

1.1 La precandidatura y los primeros años de gobierno de Alberto Fujimori

Fujimori.

1.1.1 Herencia del gobierno Aprista Peruano - APRA (1985-1990) y el primer desenlace electoral de los comicios de 1990.

1.1.2 Vladimiro Montesinos y su aparición en el escena política de Alberto Fujimori.

1.1.3 Segunda vuelta en las elecciones de 1990 y los dos primeros años del gobierno de Alberto Fujimori Fujimori.

1.1.4 Relatos de la dictadura y del gobierno democrático de Alberto Fujimori Fujimori a partir de 1992.

1.1.4.1 Reseñas del terrorismo en el gobierno autocrático.

1.1.4.1.1 Algunas reseñas del terrorismo en el gobierno autocrático.

1.1.4.1.2 Alcances del destacamento Colina y sus acciones en la era fujimorista..

1.1.4.1.3 Toma de la embajada de Japón y la operación Chavín de Huantar....... 85

1.1.4.2 Las primeras reacciones del Congreso de la República.

1.1.4.3 Presunta inversión de gastos público en estudios superiores de los hijos del presidente.

1.1.4.4 Conspiración gubernamental con el narcotráfico. 102

1.1.4.5 El transfuguismo parlamentario en la era Fujimori.................... 108

1.1.4.6 Vacancia por incapacidad moral y posterior extradición................ 113

1.1.4.6.1 Resurgimiento de la fiscalización parlamentaria al ejecutivo............ 126

1.1.4.6.2 La extradición y procesos penales derivados........................... 133

1.1.4.6.2.1 Siete años del proceso de extradición de Alberto Fujimori.............. 134

1.1.4.6.2.2 Procesos penales materia de extradición............................ 138

1.1.4.7 El Indulto a Alberto Fujimori Fujimori........................... 143

1.1.4.7.1 Procedimiento del indulto humanitario de Alberto Kenya Fujimori Fujimori.

1.1.4.7.2 Coincidencias políticas - solicitud de vacancia del presidente de la república Pedro Pablo Kuchinsky Godar.

1.1.4.7.3 Discurrir del procedimiento del indulto humanitario 
2.3 Cuadro comparativos de percepción de corrupción en el Perú 19982015

PARTE II: LA INTERVENCIÓN DE LOS MEDIOS DE COMUNICACIÓN EN LA CORRUPCIÓN POLÍTICA Y LAS COMISIONES INVESTIGADORAS ANTE LA CORRUPCIÓN POLÍTICA Y LOS MECANISMOS DE CONTROL DEL PARLAMENTO EN EL DERECHO

COMPARADO.

Capítulo IV - La intervención de los medios de comunicación en la corrupción política y las comisiones investigadoras como formas de control político en el Congreso.

Aproximación a una definición de la corrupción política y los medios de comunicación como voceros del control ciudadano

1.1 Opiniones doctrinales y la aproximación de su definición.

1.2 Importancia de los medios de comunicación y su repercusión ante comisiones investigadoras

2- Las Comisiones investigadoras como formas de control político en el derecho comparado (Perú - España).

2.1 Origen y evolución histórica de la comisiones investigadoras

2.2 Conceptualización en la doctrina internacional.

2.3 Finalidad y Creación de las comisiones investigadoras como medio de control político en Perú y España.

2.3.1 Creación y Procedimiento de las comisiones investigadoras en el Perú...

2.3.1.1 Las implicancias de la creación de las comisiones investigadoras en el Perú.

2.3.1.2 Regulación del procedimiento de las comisiones investigadoras en el Perú.

2.3.2 Creación y rasgos generales del procedimiento de las comisiones de investigación en España

2.3.2.1 Las implicancias de la creación de las comisiones de investigación en España.

2.3.2.2 Generalidades de la regulación procedimental de las comisiones de investigación en España. 
3- $\quad$ Comisiones investigadoras en el Estado peruano.

3.1 Las Atribuciones funcionales de las comisiones investigadoras peruanas.

3.3 Las Decisiones de las comisiones investigadoras en el órgano jurisdiccional.

Comisiones de investigación en el Reino de España

4.1 Naturaleza y funciones de las comisiones de investigación en España....

4.2.1 Potestades en el derecho comparado

4.2.3 Comparecencia ante las comisiones de investigación.

4.2.5 Límites de investigación en las comisiones de investigación de España..

4.3 Comisión de estudio y su diferencia con la comisión de investigación....

5.1 Comisión investigadora Martín Belaunde Lossio - caso peruano

5.1.1 Líneas de investigación desarrolladas

5.1.2 Criterios para la determinación para condición de investigado.

5.1.4.1 Conclusiones de la comisión investigadora Martín Belaunde Lossio......

6.1 Línea de Tiempo Histórica de casos de corrupción en periodos democráticos

6.2 Infografía Porcentual de Casos de Corrupción por Partido Político Español.

6.3 Sinopsis de las comisiones de investigación en el Congreso y Senado español en la era democrática..... 
6.3.2 Comisiones de investigación en el Senado.

297

CONCLUSIONES........................................................... 299

RECOMENDACIONES..................................................... 312

BIBLIOGRAFÍA............................................................... 313 


\section{INTRODUCCIÓN}

La corrupción es uno de los problemas que aqueja a nivel mundial, ubicándose en todos los ámbitos, el sociológico español Josep Ramoneda señala “... la corrupción ha existido siempre, si antes no era tan manifiesta es sólo porque la ideología política la ocultaba..."l, fenómeno que ha ido in crescendo de la mano con la evolución del ser humano, transformándose en un círculo sin fin, tan cotidiano que dentro del pensamiento diario del ciudadano se encuentra la justificación de que para llegar hacer algo correcto desde el ámbito político es totalmente valedero recurrir a pequeñas acciones o determinaciones que social o éticamente puedan estar catalogadas como corruptas; es así pues, de que la humanidad ha alcanzado una especialidad.

Uno de los manuales heredados, por así llamarlo, data del siglo IV a.c. (321 y 300 a.c.) dejado por el consejero, fundador de la Dinastía Mauría, se trata del hindú Bahmán Kautilya, citado por Brioschi, quien sostiene que, "quien gobierna debe utilizar cualquier medio para lograr sus objetivos, mientras que las reglas y honradez parezcan válidas para los súbditos"; tratado previsto de afirmaciones como "cuánta agua puede beber un pez que nada libremente en el agua" o "No probéis la miel o el veneno puesto en la lengua" o "es tan difícil como manejar el dinero del rey sin probar al menos una pequeña parte del mismo" referido a la dificultad de probar la falta de honradez de un funcionario público.

De lo que se infiere que el ámbito político definitivamente no ha sido ajeno al problema; sin embargo, no fue sino hasta mediados del siglo XIV que la clase política, en particular, la inglesa, creyó encontrar uno de los métodos constitucionales más eficaces para el control político en el sector público, las comisiones investigadoras parlamentarias; sistema que con el transcurso del tiempo se revistió de características particulares dependiendo del sistema de gobierno del que se tratara, Presidencialista (Perú), o Monarquía Parlamentaria (España); y su estructuración en el Congreso de la República o en las Cortes Generales, unicameral y la bicameral respectivamente; con el propósito de indagar e investigar sobre la responsabilidad, y en su caso, rendición de cuentas de los políticos y/o funcionarios públicos que presuntamente actuaron con visos de corrupción; con un carácter más allá de los procesos judiciales y con consecuencias políticas.

${ }^{1}$ GARZÓN, Baltasar. Prólogo En: BRIOSCHI, Carlo Alberto, Breve Historia de la Corrupción de la Antigüedad a Nuestros Días, Madrid, Editorial Taurus, 2010, pág. 20 
Los alcances y caracteres de la función del Control Parlamentario de las comisiones investigadoras atribuidas a las altas esferas representativas de un país, denotan una presumible sinonimia con lo expresado por José Ingenieros en las Fuerzas Morales, respecto a que la personalidad sólo es coherente y definida en quien llega a formularse deberes inflexibles, que impliquen un pacto rectilíneo con los mandatos de la dignidad $^{2}$; sin embargo su connotación ha recaído, desde tiempos remotos, en los sistémicos e históricos actos de corrupción.

La presente investigación se remonta a una consecución de sucesos, partiendo de la premisa de que para alcanzar o descubrir la cura a una enfermedad se parte o inicia con el estudio de los trastornos anatómicos y fisiológicos de los tejidos y los órganos enfermos, así como los síntomas y signos a través de los cuales se manifiestan las enfermedades y las causas que las producen ${ }^{3}$; es decir, el origen y por qué se producen las patologías; bajo esa misma perspectiva el análisis se traslada en la historia, intentado ubicar los orígenes de la corrupción y posterior accionar político, es decir, su control parlamentario surgido a través de las comisiones investigadoras, coincidiendo en este aspecto muchos autores con la referencia a la primera constitución escrita de Inglaterra, que data del año 1258; sin embargo ésta a su vez deviene de una necesidad de contrarrestar la pandemia en que se había transformado la corrupción.

Actualmente conforme se encuentra integrado el mundo, resulta utópico una vida desarrollada sobre la base conceptual y preceptos fundamentales como las dejadas por el jurista de origen fenicio, Domicio Ulpiano quien en su momento señaló que la justicia "est constans et perpetua voluntas ius suum cuique tribuendi"; es decir que "la justicia es la constante y perpetua voluntad de dar (conceder) a cada uno lo suyo". Teniendo y pregonando como preceptos fundamentales: "honeste vivere, alterum non laedere et suum quique tribuere"; es decir "vivir honestamente, no hacer daño a nadie y dar a cada uno lo que le corresponde"; siendo estas líneas por donde discurrió el sendero de mi vida, a pesar de que en el camino fui encontrando las barreras que implican el poder y la corrupción, la ilusión y la esperanza de poder contribuir, eran más fuertes y en consecuencia el motor; esa convicción fue el timón conductor para enfrentar la mala yerba de la corrupción. Llevo más de 23 años en el área del derecho y más de 20 años de Licenciada en Derecho y los valores de la verdad y probidad son el hilo conductor

\footnotetext{
${ }^{2}$ INGENIEROS, José, «El Control Político en América Latina», Centro de Capacitación y Estudios Parlamentarios Congreso de la República del Perú septiembre, 2015, pp. 93.

${ }^{3}$ www.google.com
} 
en mi vida personal y profesional, asumiendo las consecuencias de lo que ello representa en el desarrollo profesional en el continente sudamericano.

A lo largo del camino precitado, las preguntas comunes y más recurrentes de toda persona de a pie son ¿Cuándo nació la corrupción?, ¿Por qué se originó? ¿Por qué perdura? ¿Por qué no resulta su constante combate?, ¿Qué la causa?, ¿Por qué hay países con $12 \%$ de corrupción? infiriendo, que probablemente la cura resulta más simple de lo que todo el mundo piensa, sin embargo, la complejidad recae en su misma simpleza.

Estas interrogantes llevan a plantearse investigar cuáles fueron los alcances de la corrupción a nivel de la historia y su repercusión en el tiempo, desde la era antigua, pasando por la colonial y culminando por la época republicana; otorgando la vía para la aproximación a una definición de corrupción política y una acertada o no implementación constitucional de la comisión investigación parlamentaria en el ámbito político, para cuyo efecto se tomó como referencia los gobiernos de Perú y de España; el discurrir de la descripción de los hechos suscitados a lo largo del tiempo aportará la aproximación a una definición, las razones o motivos, las acciones preventivas y de combate a mediano y largo plazo.

Al optar en esta investigación por un análisis histórico y a la vez descriptivo, el estudio se enfocó en torno a los registros y develaciones de la corrupción desde épocas muy remotas; pretender plasmar todos los acontecimientos sería un planteamiento utópico, por lo que la alternativa estuvo en circunscribirlo hacia algunos alcances históricos de la corrupción y la consecución en el transcurso del tiempo, cuyo desenlace se tradujo en el primer capítulo a acontecimientos suscitados desde la creación del hombre, partiendo del ámbito bíblico, reflejado en el antiguo y nuevo testamento; los aportes directos e indirectos de grandes pensadores y filósofos lo encaminaron por la era socrática denominándolo acusación, defensa Socrática y las enseñanzas historiográficas; este capítulo lleva a sostener en forma empírica que ésta nació con el hombre y se viene tratando como problema o causa en lugar de consecuencia o efecto; este errado camino, ha permitido que la deshonestidad se licencie y doctoree en lo que conocemos por corrupción, llegando a convertirse lo ilegal en ventas legalmente permitidas, producidas no solo en los reinados medioevales sino también en un ámbito premunido presumiblemente de espiritualidad como el clero trasmutado al clericalismo en la era medioeval. 
Como toda acción tiene su reacción, las repercusiones habidas se trasladaron a las conquistas territoriales, incursionando en el segundo capítulo en la corrupción colonial habida en el virreinato del Perú, así como en torno a las injerencias monárquicas y corruptelas sigilosamente guardadas; algunos de los datos del Memorial de Juan de Aponte Figueroa y de las Noticias Secretas de América de Antonio de Ulloa y Jorge Juan fueron el preámbulo del periodo de la Corrupción Colonial del Perú Virreinal, como la habida en la era del Príncipe de Esquilache, del Marqués de Castelldosrius y de Antonio de Ulloa.

Los efectos de la era antigua, medieval y colonial se reflejaron en la época republicana, en los gobiernos centrales ávidos de poder, parte de ella está en la década de los 90 hasta 2016 donde el Perú llegó a tener 5 Presidentes democráticamente electos y un presidente interino (Valentin Paniagua Coarazao); quienes luego de sus mandatos terminaron dos privados de su libertad, (Alberto Fujimori Fujimori y Ollanta Humala Tasso, éste último actualmente con comparecencia), dos procesados (Alan García Pérez y Pedro Pablo Kuczinsky), y uno con trámite de extradición en curso (Alejandro Toledo Manrique); el primero de ellos, Alberto Fujimori Fujimori fue considerado en el ranking mundial como el séptimo ex líder más corrupto ${ }^{4}$, durando su democracia apenas un (01) año ocho (08) meses, debido al autogolpe de estado decidido por el entonces presidente, reinando una dictadura a partir del 05 de abril de 1992 hasta el 21 de noviembre del año 2000 (durante 08 años y 07 meses), siendo finalmente vacado del cargo presidencial por incapacidad moral.

La secuela histórica suscitada en el Perú, resultó, por decir lo menos, interesante, encaminándose el estudio del tercer capítulo por la era de Alberto Fujimori, elección producida por los efectos negativos de la hiperinflación heredada del primer gobierno de Alan García Pérez; haciendo así su primera aparición política en los comicios de 1990, un desconocido ingeniero agrónomo y casi a la par su asesor Vladimiro Montesinos; el decurso del gobierno autocrático se caracterizó por el combate al terrorismo con claras violaciones a los Derechos Humanos: creaciones ocultas de

\footnotetext{
4 La Gaceta «El ranking de los ex líderes más corruptos del mundo» 2011 www.lagaceta.com.ar/nota/431691/mundo/ranking-ex-lideres-mas-corruptos-mundo.html
} 
destacamentos destinados hacer ejecuciones, malversación del gasto público para ser utilizados, entre otros, en los estudios superiores de sus 04 hijos; surgimientos de conspiraciones gubernamentales con el narcotráfico; transfuguismo parlamentario; culminando la autocracia, con la declaración congresal de la vacancia de Alberto Fujimori por incapacidad moral, una posterior extradición y, un cuestionado, indulto políticamente humanitario.

Los escenarios históricos de la era colonial y republicana propiciaron que se pueda elaborar una comparación de costos y niveles de corrupción en el Perú entre los años 1820 a 1899 y 1900 a 2015, tomando como base el producto bruto interno y el gasto gubernamental por décadas; culminando el capítulo con un cuadro comparativo sobre la percepción de la corrupción en el Perú desde 1998 a 2015.

Dados los acontecimientos, la injerencia del cuarto poder en los siglos XIX, XX y XXI que representan los medios de comunicación se circunscribieron en los gobiernos actuales alrededor de dimensiones del poder político, con alcances y trascendencias económicas y subsecuentemente de desarrollo poblacional y por ende de un país; alcanzando la intervención de este poder con la vocería del control ciudadano; por estas razones y en consonancia con lo ya desarrollado en la investigación, la segunda parte del estudio se desenvuelve en torno a la intervención o injerencia de los medios de comunicación en los mecanismos de control del parlamento que representan las Comisiones Investigadoras en el Derecho Comparado, en este caso tomando como referencia la República del Perú y el Reino de España respecto a éstas comisiones ante la corrupción política.

Es así que el IV Capítulo permite una aproximación a una definición de la corrupción política y de las comisiones investigadoras como formas de control político, para ello se parte desde su origen, evolución histórica, conceptualización en la doctrina internacional, finalidad, creación, procedimiento, implicancias en su regulación, atribuciones funcionales y límites, culminando con la referencia de uno de los casos más sonados ocurridos en el Perú, como lo fue la "Comisión investigadora encargada de investigar las denuncias periodísticas sobre las presuntas actividades ilícitas del prófugo Martín Belaunde Lossio para obtener irregularmente contratos a favor de empresas vinculadas a él, y la posible vinculación con ellas de altos funcionarios del Estado". En lo que corresponde a la ruta por el Reino de España, el análisis permitió la elaboración de una línea de tiempo de casos de corrupción en lo que vienen siendo sus 40 años de gobiernos democráticos, derivando éste en una infografía porcentual de 
casos de corrupción por partido político, para finalizar con una sinopsis de las comisiones de investigación creadas en el Congreso y en el Senado español en su era democrática.

Debido al rumbo que fue tomando esta investigación se optó por aplicar la metodología de investigación de acuerdo a la clasificación de Dankhe, es decir; explorativa, porque al examinar el tema materia de investigación se pudo incursionar en algunas de las causas originales de la corrupción y de la corrupción política a lo largo de la historia; descriptiva, porque a través de la reseña histórica se ha analizado el desenvolvimiento y desarrollado el fenómeno de la corrupción, en particular, la corrupción política; sobre la base de determinados periodos de la República de Perú y del Reino de España; explicativa, porque el análisis explorativo y descriptivo condujeron hacia determinas causas que generaron el fenómeno de la corrupción, así como las razones, controles e instrumentos aplicados para combatirla, entre ellos, las Comisiones Investigadoras.

Para tal efecto se recurrió a libros, revistas, páginas webs, diversas sentencias como las emitidas por Tribunal Constitucional, la Corte Interamericana de Derechos Humanos, el Tribunal Supremo, la Corte Superior, entre otros; informes, como las expedidas por el Congreso de la República; claro ejemplo del desarrollo de la historia y de las consecuencias suscitadas.

Para finalizar esta etapa introductoria, cabe citar al filósofo, astrónomo y matemático Italiano, Giordano Bruno, con quien la investigación coincide cuando cuestiona señalando que acaso "Lo último corrompido ¿no es el principio de lo engendrado?”, dado que de la ubicuidad histórica del tema materia de investigación, sobreviene el declive ético de la integridad humana, canalizándose la pandemia de la corrupción como causa en lugar de consecuencia, ruleta que se encuentra bajo el mando de las personas con poder político, con aparente intención de corregirlas, debiendo recaer la misión formativa para la creación de una nueva generación con cimientos de probidad, en cada persona que conforma la humanidad. 


\section{CONCLUSIONES}

\section{PRIMERO}

La metodología explorativa y, descriptiva aplicada en la investigación, lleva afirmar que las calificaciones de actos de corrupción como tal, tienen que ser tomados de acuerdo a la realidad histórica de cada momento y de cada ubicación geográfica, no obstante, la metodología explicativa también aplicada, lleva a concluir en cada tiempo y espacio que todo parte o se inicia desde un tema de valores.

\section{SEGUNDO}

La corrupción no es un tema novedoso en la historia del mundo, por el contrario, nació desde la creación del ser humano; resulta ser tan antigua como adan y eva; es pues un hábito trasmitido por el hombre/mujer desde épocas ancestrales $\mathrm{y}$ perfeccionado con el tiempo, y, a la par de la evolución del ser humano se ha ido reiventando, de lo que se puede argüir que la corrupción no es el origen del problema sino el resultado de lo difundido y propalado.

\section{TERCERO}

Los millones de años de existencia de la humanidad, sumadas a las enseñanzas dejadas por grandes pensadores, siguen sirviendo de base y análisis en pro de una solución o alternativas de combate a la corrupción; sin embargo, las alternativas provenientes de diferentes análisis e investigaciones de larga data, se concretan a un tema de valores y una integridad inquebrantable del ser humano, de repercusiones benéficas, no sólo de carácter individual sino social.

\section{CUARTO}

Los registros bíblicos, como los datos dejados por historiadores y filósofos hindúes, romanos, griegos, entre otros, citados en el presente estudio, han demostrado que la problemática de la existencia de la corrupción no se encuentra en el otorgamiento de normas, sino en la aplicación de las mismas; acreditando además la historia que la lucha contra lo que llamamos corrupción no es oriunda de nuestro siglo, sino que la problemática data de todos los tiempos, que, a pesar de su constante combate, sigue resultando infructuosa; y, las medidas de corrección como administrativas y/o penales insuficientes, en otras palabras, la ciencia 
avanza, el ser humano se desarrolla y la corrupción se reinventa.

\section{QUINTO}

La conjunción de la carencia de valores con la desigualdad humana desembocó en el problema endémico de la corrupción, y, con ello, las ansias de llenar las arcas de la mayor cantidad de dinero, transmutándose con el paso del tiempo a un tema de poderío, de lo que se infiere que la razón que desemboca en la corrupción, es la ambición desmedida por el dinero y/o las ansias por el poder, causando el desenvolvimiento y desarrollo de la corrupción propiamente dicha en sus diferentes modalidades.

A ello se suma, la problemática conceptual, que a lo largo de los años aún se encuentra latente a nivel internacional, y no es sino que la definición del actor, del sujeto activo; considerada como persona transgresora de las normas sociales, morales y/o jurídicas. La existencia de esta variabilidad dentro de las normas sociales hace que la calificación de un concepto como corrupto o corrupción, dependa y esté ligada al momento histórico, político y social, como a su sistema de valores vigente al momento de producirse el acto, desencadenando en la inviabilidad de una definición y solución acertada.

\section{SEXTO}

La ignorancia, es decir, mantener a la población con analfabetismo, incultura, desconocimiento; fue uno de los métodos en la era antigua mejor utilizados, y, usados como conducta habitual en las personas que de alguna manera detentaban algún tipo de poder, siendo posteriormente aprovechado en el ámbito político.

El ámbito espiritual no fue ajeno a la seducción del poderío y la corrupción; inculcando la práctica de la ignorancia y apoderándose a través del clericalismo, es decir, la instrumentalización de la religión para obtener un fin político, plasmado en la era medioeval en la simonía y el nicolaismo.

Ambos escenarios nos llevan por el camino de la educación valorativa, y, ésta a su vez por el de una adecuada nutrición, toda vez que para poder aprender y entender previamente se debe estar bien alimentado.

\section{SÉPTIMO}

Remontándonos a la era incaica peruana el poder estaba circunscrito exclusivamente al Inca, con un modelo de organización teocrático donde la ley se subordina al interés 
que el representante encarna; es decir, a la divinidad misma, y, cuya regulación se abocaba a un tema de valores que, lleva a concluir el tipo de corrupción que en habida cuenta reflejaban las referidas leyes, Ama Sua: No seas Ladrón, Ama Quella: No seas Ocioso y Ama Llulla: No seas Mentiroso.

No obstante ello, y, ocurrida la conquista del imperio incaico, la propia historia nos sitúa en la promesa de pago por un rescate en oro y plata promovido por el apresado Inca Atahualpa; esta ubicación de espacio y tiempo posiciona a la acción con dos preceptos que difieren en su propia concepción:

a Desde el pensamiento indígena, podría estar tratándose de una ofrenda a quienes consideraban en ese momento superiores, en principio, dada la armadura de la que se revestían los conquistadores, el armamento, los caballos que los acompañaban y la creencia de su origen mitológico, llegándolos a considerar como una especie de dioses que habían llegado ante el pueblo.

b. Desde el pensamiento conquistador, proveniente de una cultura diferente, con costumbres e ideas distintas y la práctica de la pugna por la compra de oficios vendibles, la acción del Inca Atahualpa, sería en el ámbito del conquistador el pago a cambio del cargo que ostentaban el inca.

Escenarios que, evaluados en el binomio espacio tiempo, se advierte que desde la perspectiva actual, ambas acciones se encuentran en el entorno de los actuales actos de corrupción; es decir, tanto del colonizador como del colonizado.

\section{OCTAVO}

El nuevo virreinato del Perú, trajo consigo un nuevo sistema, y con él la corrupción administrativa, enseñanzas que la raza indígena fue adquiriendo con el tiempo y vivenciándolo en primera persona con los diferentes virreinatos habidos previa a la independización en casi cuatro siglos de dependencia con el Reino de España, en la que gobernaron 40 virreyes (Siglos XVI al XIX Después de Cristo).

Los valores y desvalores aprendidos, entre ellos también los de corrupción, no hicieron nada más que trasmitirse en el tiempo, en toda la circunscripción de la población, que fueron desde el indio, criollo, mestizo, español, hasta las altas esferas administrativas, comerciales, militares, políticas y monárquicas; estableciendo el precedente a seguir. 


\section{NOVENO}

El clientelismo, tráfico de influencias, cohecho, asociación ilícita, colusión, entre otros tipos penales tipificados en nuestros tiempos como acciones antijurídicas de corrupción, eran actos habituales en la era virreinal, muestra de ello fueron los años 1615 a 1621 a cargo del Francisco Borja y Aragón, Príncipe de Esquilache considerado por la historia como uno de los virreyes más incapaces y corruptos de la etapa colonial.

Casi un siglo después, las muestras de corrupción se siguen apreciando desde el gobierno central, se trata del virreinato del Marqués de Castelldosrius Manuel de Oms de Santpau Olim-Sentemenat i de Lanuza, quien gobernara desde 1704 a 1709; y que fuera destituido del cargo por mandato del rey, por denuncias que en la actualidad se conocen como: Cohecho, Tráfico de Influencias, Defraudación Tributaria, Omisión, Rehusamiento o Demora de Actos Funcionales, Aprovechamiento Indebido del Cargo.

\section{DÉCIMO}

Una de las evidencias del intento de la lucha contra la corrupción en la era virreinal fue el gobierno de Huancavelica a cargo de Antonio de Ulloa 1758 - 1764, virreinato en la que se aprecia la crítica por parte del Virrey Ulloa de la venta de cargos de corregidores realizado por los virreyes, pretendiendo exigir a los funcionarios de las Cajas Reales a dar cuenta mediante las cartas cuentas con el fin de controlar o supervisar el reparto del mineral, lo que en la actualidad equivaldría a la transparencia y rendición de cuentas, sin embargo, se encontraba en una contienda solitaria y por el contrario sus detractores estaban conformados por los funcionarios, servidores y el clero, por lo que siendo que las fuerzas por parte de la corrupción eran más compactas que su lucha contra ella, la autoridad como tal careció de fuerza, al punto que sus ordenanzas y disposiciones no eran acatadas.

\section{DÉCIMO PRIMERO}

En la línea lógica del principio fundamental de causalidad, el trascurrir de la historia tuvo su efecto en la era republicana peruana; sin embargo, de los 61 presidentes que viene teniendo la República de Perú, la investigación se centró en la década de 1990-2000, era de Alberto Kenya Fujimori Fujimori.

La descripción histórica realizada de este periodo de gobierno, nos lleva afirmar la existencia de una sistematización de la corrupción a nivel gubernamental, y, 
además la configuración de una organización criminal enquistada desde el Poder Ejecutivo y ramificada hacia los demás poderes del Estado - Poder Legislativo y Poder Judicial - a los que se sumaron las administraciones públicas; poderes, entidades e instituciones que llevan la dirección política, económica y social de un país.

\section{DÉCIMO SEGUNDO}

Los hechos han señalado que el descontento, la desilusión y el descrédito dejado en el ciudadano votante por la clase política convencional, ocasionaron que se abrieran las puertas y el halo de esperanza hacia un ciudadano de descendencia japonesa, prominente empresario y decano de la Universidad Nacional Agraria. Un debutante en el ámbito político, quien había acumulado gran prestigio fuera del sistema; resultando finalmente vencedor al alzarse con el sillón presidencial por encima de los partidos políticos tradicionales a pesar de ser un candidato ajeno al mundo de la política, situación que en el argot de la ciencia política se denominó el outsider presidencial de la década de los 90.

\section{DÉCIMO TERCERO}

El desempeño de Alberto Kenya Fujimori Fujimori en su gobierno nos hace acuñar una nueva modalidad de delito, a la llamaremos, "Organización Criminal Gubernamental”. La aparición del Alberto Kenya Fujimori Fujimori en el ámbito político peruano no vino solo, de acuerdo a la historia, acompañado de su mano derecha, su asesor; llamado Vladimiro Montesinos Torres cuyo actuar no se condujo dentro de los parámetros de la probidad. Ex capitán del ejército, dado de baja con deshonor, procesado por traición a la patria por espionaje, presunto abogado con aparentes años incompletos de estudios, defensor de narcotraficantes y guardador de mayor secreto de Alberto Fujimori, su país de origen, Japón y no Perú; corrupción en todo su apogeo, ese fue el candidato y posterior presidente de la República del Perú y su asesor presidencial.

El planteamiento táctico durante sus años de gobierno, contó con una nómina escalonada y clasificada de acuerdo a la función, entre los que encontraban militares, funcionarios públicos, Congresistas de la República, abogados, servidores en general, personas naturales, personas jurídicas y medios de comunicación; que-ya ostentaban y/o que estaban dispuesto a ostentar cargos de envergadura o 
simplemente pertenecer al círculo cercano; siempre bajo las órdenes de Alberto Kenya Fujimori Fujimori y Vladimiro Montesinos Torres, y, al mismo tiempo bajo sus propias decisiones, es decir, de forma independiente y a su libre albedrio; el presunto objetivo respaldaría la metodología utilizada - el fin justificaba los medios - a efectos de enmascarar el beneficio económico y de poderío personal, sin cobrar mayor importancia que se actuara bajo parámetros legales o no.

\section{DÉCIMO CUARTO}

Los gobiernos y diferentes formas de Estado revisados en el transcurso de la historia indican una conducción de los entes gubernamentales por una ruta sin los más mínimos parámetros de legalidad, ética o respeto, y la política convertida virtualmente en un idealismo que algunos aspiran alcanzar; en tanto y en cuanto la utilización de métodos politiqueros como actuaciones para beneficio propio, de su grupo o asociación política, que finalmente repercute en beneficio personal, denotan una tergiversación del término "política", entendida en toda su acepción, es decir, como el núcleo donde se estructura y organizan las decisiones de los gobiernos; como el arte del trabajo para la promoción del bien común de un pueblo.

Estos desarrollos históricos aludidos nos han llevado a proponer una definición de corrupción política en la que se incluyen la participación de agentes privados, así como el aspecto ético; en tal sentido, la Corrupción Política es: "la acción $u$ omisión que conlleva un comportamiento legal, ilegal y/o inmoral o contrario a ética de una o más personas que ocupan un papel en la estructura de la función pública y/o privada y/o política- en tanto y en cuanto no todo político es funcionario público, ni todo funcionario público es político-, donde individual o colectivamente incitan o solicitan beneficios personales, comerciales, monetarios, políticos a su favor o de terceros, con el fin de sacar un resultado dentro o fuera de los parámetros legales y/o morales o éticos”.

\section{DÉCIMO QUINTO}

Una de las consecuencias positivas y por ende relevantes de la corrupción política ha sido el alzarse los medios de comunicación a un nivel diferente al que se había estado desenvolviendo, llegándose a convertir en lo que coloquialmente se llamaría el Cuarto Poder del Estado, cuyas repercusiones se han dirigido al logro de una mayor o menor influencia sobre la actividad política e instituciones públicas de 
todo nivel, entre ellas, las referidas a la etapa indagatoria de las Comisiones Investigadoras, a razón del creciente periodismo de investigación; tornándose en la voz disonante del pueblo; sin embargo, esta representación se encuentra en una línea delgada entre la veracidad de lo informado y la información sensacionalista.

Este poderío periodístico ha traído sobre todo en los medios de comunicación sensacionalistas, la complicidad del binomio personaje político - agente periodístico, con una retroalimentación mutua; donde al personaje político poco le interesa si se habla mal de él, porque lo importante es que se hable de él y no salir del escenario del posible votante.

No obstante, lo señalado en el párrafo precedente, los medios de comunicación contribuyeron sustancialmente al núcleo esencial del Estado constitucional que representa el órgano de control, en este caso, las Comisiones Investigadoras (Perú) o Comisiones de Investigación (España).

\section{DÉCIMO SEXTO}

Por otro lado, la realidad política del siglo XXI nos señala que el control parlamentario que las comisiones investigadoras o comisiones de investigación pueden ejercer, se encuentran politizadas, pues el combate contra la corrupción se está convirtiendo en un área para destruir al adversario, no desde las bases de la lucha contra la corrupción, sino de la eliminación o degradación de un político, partidos, grupo o asociación política; distrayendo y/o confundiendo con el discurso. Procederes con los que se trastoca la condición subjetiva de las comisiones investigadoras o comisiones de investigación como lo es el control político en su función primordial de controlar la acción gubernamental en la prosecución del equilibrio de poderes. Fiscalización que presumiblemente se origina por la aparición de irregularidades o deficiencias en la actuación del órgano gubernamental o administrativo, cuya responsabilidad corresponde al ejecutivo, repercutiendo de manera directa a nivel político e indirectamente a nivel judicial.

\section{DÉCIMO SÉPTIMO}

Conforme a lo investigado, así como a nivel doctrinario una de las formas de control político por excelencia en el Congreso o Parlamento, son las Comisiones Investigadoras o Comisiones de Investigación, creadas con un fin recaudatorio de información y finalmente de fiscalización. 
Las Comisiones Investigadoras (Perú) o Comisiones de Investigación (España), bajo la definición propuesta en la investigación recae en que "son órganos internos del parlamento con un rol instrumental a la función de control políticoparlamentario, ejerciendo en sí mismas una función cognoscitiva-inspectiva por regla subordinada al control político-parlamentario sobre acciones de servidores públicos, funcionarios públicos o particulares, que se realicen en perjuicio del interés público o interés del pueblo, teniendo un carácter temporal con facultades parajudiciales, de repercusiones directamente políticas e indirectamente judiciales".

\section{DÉCIMO OCTAVO}

Siguiendo la ruta de las comisiones investigadoras o comisiones de investigación, conforme lo sostiene la doctrina, éstas han sido dotadas de atribuciones, funciones y también de límites, como los: (i) Límites materiales: Donde sitúa el carácter «secretas»o «reservadas» de las sesiones. (ii) Límites orgánicos o competenciales: Referida a las relaciones interinstitucionales, respecto a la colaboración de dotación de información y la falta de obligatoriedad de los órganos jurisdiccionales de proporcionar la información; (iii) Límites personales: enfocado al derecho constitucional del derecho a la intimidad, y; (iv) Límites temporales: Concerniente a la duración de las comisiones de investigación; plazo y prórroga establecido por el Pleno del Congreso.

Esta clasificación, adolece de dos elementos que se producen en la praxis de un procedimiento de investigación de una comisión parlamentaria, por un lado, el referido a la obstaculización por interpretaciones constitucionales por presuntos vacíos legales habidos en la norma que lo ampara; y, el segundo debido a la participación en las sesiones reservadas de congresistas o parlamentarios ajenos a la conformación de una Comisión Investigadora. Al primero, se le denominará "Límite de Actuación o de Ejecutoriedad", consistente en el límite que ha establecido el Tribunal Constitucional a través de la sentencia recaída en el expediente $\mathrm{STC} \mathrm{N}_{-}^{\circ}$ 00156-2012-PHC/TC, exigiendo el empleo de garantías de un Debido Proceso, en un procedimiento investigatorio de carácter político parlamentario; con aplicación expresa del principio de non bis in ídem; es decir, nadie podrá ser procesado, ni sancionado más de una vez por un mismo hecho; resolución en la que Supremo Tribunal no ha tomado en cuenta que las comisiones 
investigadoras o comisiones de investigación se encuentran exentas de facultades sancionadoras, correspondiendo sus efectos o repercusiones exclusivamente al ámbito electoral o funcional desde la perspectiva de la pérdida de confianza sobre el cargo público conferido, más no así en el entorno al ámbito jurisdiccional; constituyendo en la praxis en una limitación en la conducción de una comisión investigadora o de investigación.

La aplicación de todos los principios de los cuales se encuentra premunido el derecho fundamental y universal del debido proceso conlleva intrínsecamente a la deformación de la naturaleza representativa pluripartidaria del ente legislativo y por ende a la incompleta aplicación del principio de división de poderes, toda vez que la potestad de administrar justicia le corresponde constitucional y exclusivamente al poder judicial, por tanto, no todos los derechos que contempla el debido proceso pueden aplicarse del mismo modo, quedando estas supeditadas a la naturaleza de la institución.

\section{DÉCIMO NOVENO}

Adicionalmente a lo sustentado en los párrafos precedentes, otra de las consecuencias que ha traído consigo la aplicación de lo ordenado por el Tribunal Constitucional ha sido de que las personas naturales, jurídicas y entidades involucradas directa o indirectamente en la investigación de una comisión, exigieran al amparo de la sentencia, los referidos requisitos, con el agregado interpretativo de que su titular, es decir, el agente indagado haya pasado a la situación de investigado, con exposición debidamente motivada; promoviendo no sólo el retardo en la obtención de información relevante para la investigación, como el que pudiera significar el levantamiento de la reserva bancaria, tributaria y/o de comunicaciones; sino que además el recorte de la función esclarecedora de la comisión investigadora, obstaculizando la posibilidad de indagar aquellas personas que presuntamente pudieran tener un vínculo directo con los hechos investigados o con los directamente involucrados, como resulta ser el caso de familiares, amigos o presuntos testaferros, especialmente cuando se podría tratar del accionar del criminen organizado; configurándose el Límite de Actuación o de Ejecutoriedad.

Otro de los límites de actuación o de ejecutoriedad consagrados en la práctica, la encontramos en la carencia de reglamentación o lineamientos consuetudinarios respecto a la aplicación de la colaboración entre Comisiones Investigadoras y/o 
Comisiones Parlamentarias, a lo que se añade la renuencia de los congresistas integrantes de las Comisiones Investigadoras a proporcionar la información hallada por estos órganos; esta ausencia de colaboración interparlamentaria a nivel de comisiones investigadoras acarrea una doble labor institucional, gasto de horas hombre y, perdida de celeridad, tiempo y finalmente económico, no solo al Poder Legislativo sino además al Poder Judicial y los organismos encargados de brindar la información respecto del secretos bancario y tributario, convirtiéndose la falta de cooperación interparlamentaria en un Límite de Actuación o deEjecutoriedad.

El segundo límite con que esta investigación contribuye, es el "Límite al dominio de la Reserva", referido a la participación de congresistas o parlamentarios ajenos a la conformación de una Comisión Investigadora en las sesiones reservadas, que si bien es cierto, esta praxis encuentra su respaldo normativo en el inciso a) del artículo $22^{\circ}$ del Reglamento del Congreso que prevé: “Los Congresistas tienen derecho: a) A participar con voz y voto en las sesiones del Pleno y, cuando sean miembros, en las de la Comisión Permanente, de las Comisiones, del Consejo Directivo, de la Junta de Portavoces y de la Mesa Directiva, de acuerdo con las normas reglamentarias. Podrán participar con voz, pero sin voto, en las sesiones de cualquier otra comisión y de las que no sean miembros o, siendo integrantes de alguna de ellas, tenga la calidad de accesitario y el titular se encuentre presente (...)"; cierto es también que la discreción sobre la reserva de la sesión queda al libre albedrio de cada congresista que asista y a su vez la utilización pública de una valoración y/o pronunciamiento antelado; vulnerándose el carácter reservado de la comisión investigadora; protección que alberga los tres sectores constitucionalmente custodiados de toda persona, como lo son el secreto bancario, tributario y de comunicaciones; su desprotección pone en duda el sistema garantista que respalda a todo habitante de un país y del que presuntamente gozan ante las Comisiones Investigadoras; configurándose así la figura de la limitación al dominio de la Reserva de la que se encuentran investidos los congresistas integrantes de una comisión investigadora o investigación.

\section{VIGÉSIMO}

La corrupción y la corrupción política afectan hondamente la democracia en sí misma y por consiguiente el Estado de Derecho, lesionando el interés del pueblo; deteriorando la credibilidad que el Estado en su totalidad pueda haber adquirido, 
repercutiendo en el desarrollo del Estado, y, por consiguiente, dotando a las generaciones de un territorio de en una calidad de vida, ingreso per cápita y desarrollo industrial parcialmente inferiores, características universales de un país subdesarrollado; consecuentemente, merma y degrada la institucionalidad democrática.

La consecuencia de la que se deriva, deviene de una cadena de circunstancias, de un círculo sin punto de partida; es pues que el problema pandémico de la corrupción debe ser tratado desde varios frentes, debido a su enquistamiento, debiendo ser uno de los más fuertes, de larga data y pensando en futuro; combatir el problema de la nutrición, ya que comenzar por una nutrición adecuada en etapa temprana, de la mano con la preparación, es decir, con una educación cognoscitiva y moral dentro de las bases de la honradez, ética, decencia, virtud, probidad, civismo e integridad podrá avalar una población con actitudes de una política responsable.

Contrario sensu estamos formando generaciones cultivadas en el oscurantismo y la ignorancia, con grandes probabilidades de incursionar a futuro en una vida política directa o indirectamente y por consiguiente potenciales representantes en las altas esferas gubernamentales.

\section{VIGÉSIMO PRIMERO}

El efecto de la corrupción no es solo un problema de países en vías de desarrollo y subdesarrollados sino también de países desarrollados; pues se ha volcado de ser una epidemia a una pandemia; cuyo control y combate es cada vez más difícil de controlar. El combate estriba en un cambio de mentalidad, con una alimentación nutricional adecuada y una educación de valores íntegros, a todos los niveles, infantes, niñez, adolescencia y adultez.

La problemática nutricional no es exclusiva de los países en vías de desarrollo y países subdesarrollados; toda vez que la población de países de extrema pobreza migra de manera constante, siendo asumidos por lo países desarrollados, adquiriendo una problemática que con el transcurso del tiempo repercutirá en la decisión de la conducción del gobierno que lo acogió.

Además de ello, la desnutrición es otra de las consecuencias de una mala política estatal, en la que viene interviniendo la corrupción política.

\section{VIGÉSIMO SEGUNDO}


Las fórmulas que a lo largo del tiempo se ha desarrollado como materia de prevención llamadas sanción penal, sanción política y sanción administrativa; no vienen redituando los frutos esperados, por el contrario, muchas veces han servido para el desarrollo de habilidades de salidas legales antiéticas libres de una posible sanción; por lo que el endurecimiento de penas en determinados casos, resultan ser justificables.

Ante la premisa, y dado el desarrollo histórico suscitado, se debe señalar que ciertos tipos penales contemplados en los códigos tanto de Perú como de España, si bien preceptúan en su articulado la clasificación de organización criminal y delitos cometidos por funcionarios públicos; ésta graduación de la pena no distingue altos rangos como la presidencia del gobierno o república, congresistas, parlamentarios, ministros de Estado, directores o presidentes de órganos reguladores y de organismos autónomos; cargos en los cuales, los sujetos activos, es decir, sus titulares detentan un poder del que difieren sus subordinados; encontrándose facultados incluso para determinar la calidad del equipo que lo acompañara, la línea de trabajo y además se encuentran intrínsecamente premunidos del poder de la influencia con que en la práctica amedrentan a personas de rango inferior; estilos conductuales que se han venido perfeccionando a lo largo de historia. Más aún si se tiene en cuenta la ausencia de la práctica de la meritocracia en los gobiernos, y, por el contrario, la usanza de la dedocracia, es decir, nombramientos en cargos públicos - usualmente temporales - en puestos llamados de confianza.

Consecuentemente, sin pretender caer en paroxismo punitivo, la trascendencia de establecer el tipo penal de "Organización Criminal Político - Gubernamental" pretendería prevenir la mal formación de funcionarios públicos y/o personajes políticos del alto standing, cuyas posturas conductuales escapan de amoldarse al consabido proceder de un buen gobierno en el ámbito del servicio público y del político; pudiendo constituirse este tipo penal como agravante del ya existente, acompañado de la pena accesoria de inhabilitación para ejercer cargos públicos o políticos.

\section{VIGÉSIMO TERCERO}

La historia nos viene enseñando que la lucha contra la corrupción es y será una batalla que probablemente no se gane, sin embargo, podría menguar; la República de Perú en la actualidad se encuentra en un momento de trascendencia histórica a nivel 
mundial, todas personas que llegaron al sillón presidencial desde 1985 a la fecha se encuentran procesados y hasta privados de su libertad, investigados y acusados por delitos de corrupción cometidos en sus gobiernos; sucediendo lo propio en el Reino de España respecto a políticos, presidentes autónomicos, altos funcionarios, con la atingencia particular en este caso de que la gracia del indulto se ha convertido, no en un uso extraordinario, sino por el contrario en el uso habitual otorgado por el Rey, a propuesta del Ministro de Justicia, previa deliberación del Consejo de Ministro. 


\section{RECOMENDACIONES}

1. La aplicación del binomio nutrición-educación desde la base de la infancia, y, más allá de la política de Estado, con intervencionismos privado de ser necesario; creando además alternativas ocupacionales u oficiosas para aquellas personas que sobrepasaron la etapa de alimentación nutricional esencial y cuya absorción cognoscitiva resulta diferente. La educación debe tener como base primordial la enseñanza valorativa.

2. Captación participativa adolescente estatal y posterior formación de consejos o parlamentos de la juventud con planificación responsable, y, dirección y ejecución de proyectos.

3. Inclusión en el currículum básico de la educación primaria, de la educación secundaria obligatoria, del bachillerato en el caso del Reino de España y en currículo nacional en el caso del Perú, la enseñanza de normas técnicas internacionales y nacionales contra la corrupción; la finalidad es la preparación de futuros ciudadanos de participación activa y voluntaria de gobernabilidad y de ciudadanos con decisiones claras, probas y estables para la elección de gobernantes.

4. Colaboración inter gubernamental internacional de acciones específicas -no solamente normativas- contra la desnutrición, educación y anticorrupción, en tanto y en cuanto la desnutrición y pobreza de una país sub desarrollado o en vías de desarrollo será a la larga la problemática migratoria y nutricional adquirida del país en mejores condiciones, repercutiendo con el transcurso del tiempo en la decisión de la conducción de los gobiernos desarrollados o en vías de desarrollo, por la adquisición de la ciudadanía o la procreación de su descendencia.

5. Obligatoriedad de los partidos políticos de la preparación a militantes y/o simpatizantes para el desempeño de cargo público y/o actividad pública con especial énfasis en la enseñanza de normas técnicas internacionales y nacionales contra la corrupción, y, el procedimiento interno de la conducción de un ministerio del estado y entidad pública. 


\section{BIBLIOGRAFÍA}

ABellán, JoAQuín, «Política Conceptos Políticos Fundamentales», Alianza Editorial, 2012.

AlARCón Olguín, Víctor, «Ética y Política en los laberintos de la postmodernidad». Ars Iuris Salmanticensis, vol. 1, Ediciones Universidad de Salamanca, diciembre 2013

Alcántara SÁez, Manuel, Los Sistemas Políticos de América Latina, Volumen I América del Sur. Madrid, Editorial Tecnos, 1999.

Alzaga Villaamil, Oscar, Gutiérrez Gutiérrez, Ignacio, y otros. Derecho Político Español según la Constitución de 1978 II - Derechos Fundamentales y Órganos del Estado, Editorial Universitaria Ramón Areces, Sexta Edición, 2017.

Amorina Villarreal, Brasea; «Gracia y Desgracia para El virrey del Perú Francisco de Borja y Aragón, Príncipe de Esquilache (1616-1621)» América en la Memoria: Conmemoraciones y Reencuentros. Edita: Asociación Española de Americanistas y Universidad de Deusto, 2013.

ANC, FMC, 120.6, «Instrumento de venta hecha por don Juan de Olmera y de Raset a favor de Dn. Félix de Sentmenat, en poder de Joseph Francisco Fontana, notario de Barcelona, en 10 de mayo de 1732». En: Una Aproximación a la Corrupción Política Virreinal. La Confusión entre lo Público y lo Privado en el Perú de Felipe $V$. Moreno Cebrían, Alfredo y Sala I Vila, Núria.

ARChIVo GENERAL DE Indias, Sevilla (A.G.I.) «Audiencia de Lima». Legajo 495 En: Orden y Control en el Siglo XVIII. La Politica Borbónica frente a la Corrupción Fiscal, Comercial y Administrativa, O’Phelan Sacrlett, El Pacto Infame Estudios Sobre la Corrupción en el Perú, Editor Felipe Portocarrero S., $1^{\circ}$ Edición, 2005, pp. 15.

ARChivo General DE Indias, Lima 1498. «Nombramiento de Beranger como Gobernador de Huancavelica». Huancavelica, 6 de agosto de 1764 Archivo General de Indias, Sevilla (A.G.I.) Audiencia de Lima. Legajo 495 En: Orden y Control en el Siglo XVIII. La Política Borbónica frente a la Corrupción Fiscal, Comercial y Administrativa. Por O’Phelan Sacrlett. El Pacto Infame Estudios Sobre la Corrupción en el Perú. Editor Felipe Portocarrero S., $1^{\circ}$ Edición, 2005. 
ArÉVAlo GutiÉRreZ, Alfonso, «Las Comisiones de investigación y de encuesta». En Las Comisiones parlamentarias, Silva Ochoa, Juan Carlos da (coord.), Vitoria, Parlamento Vasco, 1994, pp. 365

ARZANS, Bartolomé, «Historia de la Villa Imperial de Potosí». En: Moreno Cebrían, Alfredo y Sala I Vila, Núria. Una Aproximación a la Corrupción Política Virreinal. La Confusión entre lo Público y lo Privado en el Perú de Felipe V. Providence: Brown University Press, 1965, Tomo II.

BARRY DAVID, «Las Noticias Secretas de América Escritas fielmente según las instrucciones Excelentísimo Señor Marques de la Ensenada, Primer Secretario de Estado, y presentada en informe secreto a SMC Señor Don Fernando VI por Don Jorge Juan y Don Antonio de Ulloa Tenientes Generales de la Real Armada, miembros de la Real Sociedad de Londres y de las Reales Academias de París, Berlín y Estockolmo, sacadas a luz para el verdadero conocimiento del gobierno de los españoles en la América Meridional por don David Barry» Parte 2 Londres, Imprenta R. Taylor, 1826. pp. 451

BIBLIA LATINOAMERICANA, 143 Edición, 2005

Bramont Arias Torres, Luis Miguel, Manual de Derecho Penal. Parte General, Lima, Editorial Santa Rosa, 2000.

BRIOsCHI, Carlo Alberto, Breve Historia de la Corrupción de la Antigüedad a Nuestros Días, Madrid. Editorial Taurus, 2010.

Bustos Gisbert, Rafa, «La Recuperación de la Responsabilidad Política en la Lucha contra la Corrupción de los Gobernantes: Una Tarea Pendiente - La Corrupción en Mundo Globalizado» Ratio Legis 2004. En: La corrupción en un mundo globalizado: análisis interdisciplinar. Ratio Legis. Coordinadores Rodríguez García, Nicolás y Fabián Caparrós, Eduardo A, Salamanca, 2004. pp. 67-85.

CABAllero Martín, Víctor, Conflictos Sociales por Corrupción en los Gobiernos Locales: Las Disputas por el poder Local en Escena, Lima, Proética, 2009.

CACIAGLi Mario, Clientelismo, Corrupción y Criminalidad Organizada, España,

Editores: Centro de Estudios Constitucionales, 1996.

CASTRo HAnsen, Eduardo, «Cultura política y corrupción en la Era del gobierno de Fujimori. Y algunos rasgos del gobierno de Toledo: 1990-2002». Tesina, 2004, pp.24 - 29

Cazzola, Franco y Della Porta, Corruzione y Societá, Bologna, Editrice il Mulino, 1988. 
CONSTITUCiÓN ESPAÑOLA, Editorial Aranzadi S.A., 2003.

COnSTITUCión Política Del Perú 1993, Edición del Congreso de la República, 2015.

Cotler, Julio/ Grompone, Romeo. «El Fujimorismo, Ascenso y Caída de un Régimen Autoritario», IEP Instituto de Estudios Peruanos, 2000, pp. 28.

Chirinos Martínez, José Carlos y Rivas GómeZ, Jackeline, «El Control Político en América Latina», Centro de Capacitación y Estudios Parlamentarios Congreso de la República del Perú septiembre, 2015.

De AzCÁrate Corral, Patricio, «Obras Completas de Platón» Tomo I Medina y Navarro Editores, Hortaleza 39, Madrid 1871, XLV. pp. 49-86

DEAN Robert, «Lima, 4 de abril de 1977, N²686, 1 copia desclasificada en USDS, en PDP, box 1, file Montesinos trip to D, NSA». En: Quiroz Alfonso W., Historia de la Corrupción en el Perú, Instituto de Estudios Peruanos, 2013, pp.358

Delgado-Guembes, César, «Manual del Parlamento - Introducción al Estudio del Congreso Peruano», Congreso de la República, Oficialía Mayor, 2012, pp. 457458.

Della PORTA, Donatella. «Lo Scambio Occulto, Casi di corruzione política in Italia», En: Narcotráfico, financiación política y corrupción, Cepeda Ulloa, Fernando, Ecoe Ediciones, 2011.

DíEZ-PICAZO, Luis María. «La criminalidad de los gobernantes», Barcelona: Editorial Crítica, 1996, pp. 69-70.

Eguiguren Praeli Francisco José, Algunas Consideraciones sobre las Comisiones Investigadoras Parlamentarias, Lima, PUCP, pp. 154

Elvira Perales, Ascención, «Comisiones de Investigación». En: Parlamento y Gobernabilidad Democrática en América Latina, Pedro Planas, Tomo III, Fondo editorial del Congreso del Perú, 2001, pp. 896.

ENCICLOPEDIA JuRÍDICA OMEBA, Tomo III, Buenos Aires, 1985, p. 371.

Fraile Clivillés, Manuel María, Comentario al Reglamento de las Cortes, Madrid, Instituto de Estudios Políticos, 1973, pp. 307.

FRAILE CliviLlÉS, Manuel, La comisión permanente de las Cortes, Madrid, Ed. Nacional, 1974.

García Belaunde, Domingo, «Las Constituciones del Perú». 2da. Edición revisada, corregida y aumentada, Lima, 2005, pp. 437.

García MAHAmunt, María del Rosario, Las Comisiones Parlamentarias de Investigación en el Derecho Constitucional Español, Madrid, McGraw Hill, 1996. 
GARCÍA MORILlO, Joaquín, El control parlamentario del Gobierno en el ordenamiento español, Madrid, Congreso de los Diputados, 1985.

GARRORENA MORALES, Ángel, «Autoritarismo y control parlamentario en las Cortes de Franco». Apuntes para un análisis crítico, Murcia, Departamento de Derecho Político de la Universidad de Murcia. 1977.

GIL GIL, Luis, «Las Comisiones Parlamentarias de Investigación Revista de relaciones laborales», $\mathrm{N}^{\circ} 8,2000$, pp. $147-162$

Gil Villa, Fernando, La Cultura de la Corrupción, Madrid, Maia Editores, 2008. GonZÁles MANRriQue, LuIS; Centro Pignatelli, Seminario de Estudios para la Paz: Seminario El pulso de América Latina, abril, 2003. Ponencia: Del 'chino' Velasco al 'chino' Fujimori.

Gude FERnÁndEZ, Ana, «Las Comisiones de Investigación en el Parlamento de Galicia». Versión ampliada y revisada de una conferencia impartida en la Facultad de Derecho de la Universidad de Santiago con motivo del curso de verano: Derecho parlamentario: Veinte años de Parlamento de Galicia, celebrado entre los días 15 y 17 de julio de 2002 .

GurRutXagA, Ander, El Malestar de la Democracia, España, Alberdania, S.L, 2005, pp. 236.

HANKE, Lewis, «Los virreyes españoles en América durante el gobierno de la casa de Austria». Tomo II. Madrid: Atlas. En: Villareal Brasca, Amorina. Perú. 1978

HeIDENHEIMER, Arnold J. y Otros, Términos, Conceptos y Definiciones: Una Introducción En Corrupción, Madrid, Zona Abierta, 2002.

Hurtado Pozo, José y Prado Saldarriaga, Víctor, «Manual de Derecho Penal. Parte General», Tomo II, Cuarta Edición, Idemsa, 2011, pp. 418.

JiMÉNEZ ESTRELLA, Antonio, «Poder, dinero y ventas de oficios y honores en la España del Antiguo Régimen: un estado de la cuestión». Cuadernos de Historia Moderna, 2012, pp. 259 у 261.

JIMÉNEZ DÍAZ, Andrés, «Comisiones de Investigación, Intimidad e Información Tributaria», Revista Española de Derecho Constitucional, España, Año 20, Núm. 60, Septiembre-Diciembre 2000, pp. 81.

Knowles Davis, D. Obolensky, y C. A. Bouman; «Nueva Historia de la Iglesia, La Iglesia en la Edad Media», Tomo II; 2da Edición, Ediciones Cristiandad, Madrid 1977, pp. 179 
Landa Arroyo, César, Dignidad de la Persona, derechos Fundamentales, Justicia Constitucional y otros estudios de derecho Público, Madrid, Dykinson, 2008.

LANDA ARROYO, César, «Consideraciones generales sobre los límites del control judicial del debido proceso en los procedimientos desarrollados ante las comisiones investigadoras del Congreso de la República General», Derecho PUCP, N 73 , 2014, pp 481.

LAGOS BoRDA, Néstor Alfonso, «Informe Caso Mariella Lucy Barreto Riofano.

Arqueología - Antropología Forense», UNMSM, 2006.

LAMAS PUCCIO, Luis, Inteligencia financiera y operaciones sospechosas. Lavado de activos. Lima, Editorial Gaceta Jurídica, 2008, pp. 96 - 105.

Laporta, Francisco J. y Álvarez, Silvina; La Corrupción Política, Madrid, Alianza Editorial, 1997.

LIMA Torrado, Jesús. «La transparencia como principio fundamentador de la ética política y su concreción en el sistema jurídico español "Se parte en este punto de la distinción básica, de amplia aceptación en la actual doctrina iusfilosófica, entre valores, principios y normas Ética, política y transparencia”». pp. 127-156. En: Democracia ética. Una propuesta para las democracias corruptas. Óscar Diego Bautista, Txetxu Ausín Compiladores, 2014.

LYNCH GAMENRO, NiCOLÁS «Una tragedia sin héroes: La derrota de los partidos y el origen de los independientes Perú 1980-1992», Fondo Editorial Universidad Nacional Mayor de San Marcos, 1999 pp 81

Maggioli, Rimini, Le inchieste delle Assemblee Parlamentari, Rimini - Italia, Obra Colectiva, 1985.

Martínez Huerta, Miguel, Ética con los Clásicos, México, Plaza y Valdés PyV Ediciones, 2001, pp. 81.

MEDINA RUBIO, Ricardo, La función constitucional de las comisiones parlamentarias de investigación, Madrid, Cuadernos Civitas, 1994, pp. 80.

MiCELI, Vincenzo. Inchiesta parlamentare. Enciclopedia Giuridica Italiana, Vol. VII. Milano, Societá Editrice Libraria, 1902, pp. 659-712

Montoya ChÁvez, Víctor Hugo. La Infracción Constitucional. Palestra Editores. Lima, 2005. p. 390.

Mora DonAto, Cecilia Judith, «Las comisiones parlamentarias de investigación como órganos de control político» Universidad Nacional Autónoma de México. Instituto de Investigaciones Jurídicas, 1998. 
NAESSENS, Hilda, «Ética Pública y Transparencia». Congreso Internacional 1810-2010: 200 años de Iberoamérica. Centro de Investigación en Ciencias Sociales y Humanidades Universidad Autónoma del Estado de México- Toluca México.

NORBerto Bobbio, El Futuro de la democracia, México, Fondo de Cultura Económica, 1986.

O’Phelan, Sacrlett; «Orden y Control en el Siglo XVIII. La Política Borbónica frente a la Corrupción Fiscal, Comercial y Administrativa» En: El Pacto Infame Estudios Sobre la Corrupción en el Perú, Editor Felipe Portocarrero S., $1^{\circ}$ Lima, 2005, pp. 15.

Planas, Pedro, Derecho Parlamentario, Lima, 1998, pp. 157-160

PÉREZ PAREDES, Yon Javier. «La influencia de los medios de comunicación colectiva en la formación de las comisiones de investigación parlamentaria durante el período 2001- 2011», Tesis Master en Ciencia Política. Lima, 2013.

Quiroz, Alfonso, Historia de la Corrupción en el Perú, Lima, Instituto de Estudios Peruanos, 2013.

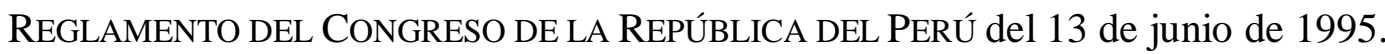
Primera Edición. Oficialía Mayor. 2015.

RobinSON URTECHO, Patricia. «Manual del Proceso Legislativo». 2da. Edición, Congreso de la República del Perú, Oficialía Mayor, 2012.

RodríGuez CASAdo, V., Primeros años de dominación española en la Luisiana. Madrid, 1942.

RoDRígueZ, José A. «La voz de las repúblicas: poesía y poder en la Lima de inicios del XVIII». En Agencias criollas. La ambigüedad "colonial” en las letras hispanoamericanas. Mazzotti, José Antonio (ed.). Madrid: Iberoamericana, 2000, p. 252. En: Una Aproximación a la Corrupción Política Virreinal. La Confusión entre lo Público y lo Privado en el Perú de Felipe V. Moreno Cebrían, Alfredo y Sala I Vila, Núria.

RUBio LlORENTE, Francisco. La forma del poder (Estudios sobre la Constitución). Madrid, Centro de Estudios Constitucionales, 1993.

SALA I VILA, Núria. «La escenificación del poder: el marqués de Castelldosrius, primer virrey Borbón del Perú (1707-1710)». Anuario de Estudios Americanos. 61/1, 2004, pp. 31-68. En: Una Aproximación a la Corrupción Política Virreinal. La Confusión entre lo Público y lo Privado en el Perú de Felipe V. Moreno Cebrían, Alfredo y Sala I Vila, Núria. 
SAlluSTIO CRISPO, Cayo, La conjuración de Catilina y Guerra de Jugurta traducida por M. Menéndez Pelayo, Biblioteca Clásica, Tomo XV, Madrid, 1882. SantaOlalla, Fernando, El Parlamento y sus instrumentos de información (preguntas, interpelaciones y comisiones de investigación), Madrid, Edersa, 1982.

Solana Dueso, José. Más allá de la ciudad. El pensamiento Político de Sócrates. Institución Fernando el Católico (C.S.I.C.) Excma, Diputación de Zaragoza, 2013. SORIANO DíAZ, Ramón L. «Anales de la Cátedra Francisco Suárez, La Corrupción Política: Tipos, Causas y Remedios». Universidad Pablo de Olavide de Sevilla España, Anales de la Cátedra Francisco Suárez, 45, 2011, 382-402.

Tarazona Palma, Roberto Carlos; Neciosup SAnTa CruZ, Víctor Hugo; y DuRAnd VÁSQUEZ, Patricia María. «Reglamento del Congreso de la República del 13 de junio de 1995», Primera Edición, Oficialía Mayor, Congreso de la República del Perú, 2012.

Torres Arancivia, Eduardo. Corte de Virreyes. El entorno del poder en el Perú del siglo XVII, Lima, Fondo Editorial Pontificia Universidad Católica del Perú, 2006.

TOVAR TAMAYO, Orlando. Las funciones de investigación y control de la Cámara de Diputados, Colectivo Derecho Parlamentario iberoamericano, Editorial Porrúa, México, 1987.

VígALA FORURIA, Eduardo. «Las Comisiones Parlamentarias en las Asambleas Legislativas Autonómicas» Cuadernos constitucionales de la Cátedra Fadrique Furió Ceriol, № 3, Valencia, 1993.

Villareal Brasca, Amorina, «Carta de la condesa de Lemos a Rodrigo de Esquivel» Madrid. 24-III-1616. Archivo Ducal de Alba (ADA), carpeta 176-2, doc. 10 En: América en la Memoria: Conmemoraciones y Reencuentros - Tomo II. Gracia y Desgracia para el Virrey del Perú Francisco de Borja y Aragón Príncipe de Esquilache (1616-1621). Coordinación y Edición Cava Mesa, Begoña. Edita: Asociación Española de Americanistas y Universidad de Deusto. 2013

\section{PÁGINAS WEB}

$\mathrm{ABC}$, (http://www.abc.com.py/edicion-impresa/internacionales)

ABreu SACRAmENTO, José Pablo, «El control parlamentario a través de las Comisiones de Investigación». Cuestiones Constitucionales. Revista Mexicana de Derecho 
Constitucional. $\quad \mathrm{N}^{\circ} \quad 18, \quad 2008, \quad$ p. $\quad 2$. (http://www.juridicas.unam.mx/publica/rev/cconst/cont/18/ard/ard1.htm)

ADELANTADO SORIANO, Vicente, «Paralelismos» (http://www.reeditor.com)

Alba NAVARro, Manuel. «Sinopsis» Diciembre, 2003. Revisado 2006, y Actualizado por Ángeles González Escudero. Enero 2011. (http://www.congreso.es)

ÁlVAREZ SABOGAL, Julio «La política exterior del Fujimorato: del autonomismo y el aislamiento económico al globalismo y el aislamiento político» Abril de 2009, (http://frutos-prohibidos.blogspot.com/p/la-politica-exterior-del-fujimorato.html)

AMÉRICA TV, «Yo te indulto vs. yo te vaco», 2017, (http://rosamariapalacios.pe/2017/12/27/yo-te-indulto-versus-yo-te-vaco/)

AMÉRICA TV, «Indulto a Fujimori, Existen dos actas médicas con recomendaciones diferentes», 2018, （www.americatv.com.pe/cuarto-poder/indulto-fujimoriexisten-dos-actas-medica-recomendaciones-diferentes)

ARAGÓN, Manuel: «El control parlamentario como control político», Revista de Derecho Político, Núm. $\quad 23, \quad$ 1986, $\quad$ pp. (http://revistas.uned.es/index.php/derechopolitico/article)

ARANDA ÁLVAREZ, Elviro, «Transformaciones en los Instrumentos de Control Parlamentario» (www.juridicas.unam.mx)

ARMIENTA CALDERÓN, Gonzalo, «Los Conceptos de jurisdicción y competencia»pp. 120. (http://www.juridicas.unam.mx)

Arrizabalaga LizÁrraga, Carlos, «Arte poder en el Perú del siglo XVIII. El virrey marqués de Castelldosrius», 2011. En: (http://udep.edu.pe/hoy/2011/arte-poderen-el-peru-del-siglo-xviii-el-virrey-marques-de-castelldosrius)

ASOCIACIÓN CIVIL TRANSPARENCIA, «Departamento de Trámite y Estadística procesal del Congreso de la República» (www.Transparencia.org.pe)

AuZMENDI DEL SolAR, Montserrat, «Letrada del Parlamento Vasco. Relaciones Poder Ejecutivo-Poder Legislativo: El Control Parlamentario a Través de las Comisiones de Investigación» Mesa sobre "Relaciones Gobierno-Cortes: sistema parlamentario" 23 de enero. (www2.congreso.gob.pe)

Belaunde Lossio, Martín, «Exposición de motivos del proyecto de ley de Fortalecimiento de la Defensa Jurídica de los Intereses del Estado uno de los principales problemas del actual sistema en el Perú». Informe Final de la Comisión Investigadora (www.congreso.gob.pe) 
CCFF. «Suplemento Comando en Acción, Lo hicimos por el Perú» 2014, (http://www.ccffaa.mil.pe/publicaciones/Suplementos/2014_suplementoChavin Huantar.pdf)

CANTO GARCÍA, Manuel. «Reflexiones sobre el Derecho a la Intimidad y las Comisiones de Investigación Parlamentarias». Boletín Núm. 1710. (www.mjusticia.gob.es)

CAPITAL.COM «Vladimiro Montesimos explica como pago los estúdios» (http://www.capital.com.pe/actualidad/youtube-vladimiro-montesinos-explicacomo-pago-los-estudios)

CASAs Baamonde, «Boletín Oficial del Estado - BOE núm. 3, de 04 de enero de 2005» Sentencia 227/2004, de 29 de noviembre. (https://www.boe.es/boe/dias/2005/01/04/pdfs/A00181-00181.pdf)

CASTRO, Jonathan, «Henry Pease y los asesinos de la Cantuta», 2014, (http://feis.utero.pe/2014/08/10/henry-pease-y-los-asesinos-de-la-cantuta)

CASTRO, Raúl, «La Corrupción y el Fracaso de las Reformas Coloniales (1757-1820)» (http://arturocastro.pe)

Chauca Ortiz, Pedro MiQueas, «CNR: Gobierno peruano presionó a la justicia para archivar denuncia sobre fondos que uso Keiko Fujimori» (https://wwsynthesis.files.wordpress.com/2010/07/gastos-fam-fuji.jpg)

Clarin, «Afirman que Fujimori tiene bajo arresto a Montesinos». 2000. (http://edant.clarin.com/diario/2000/09/18/i-02401.htm)

CLARIN, «Los secretos de Fujimori», 1997 (http://edant.clarin.com/diario/1997/08/03/i$\underline{01501 \mathrm{a} \cdot \mathrm{htm})}$

COMISIÓN DE LA VERDAD Y LA RECONCILIACIÓN NACIONAL, «Declaración del colaborador identificado con Clave 371 - MCS», 20 de septiembre de 2001, pp. 563/564 (http://www.cverdad.org.pe)

COMISIÓN DE LA VERDAD Y LA RECONCILIACIÓN NACIONAL, «Carta de fecha 20 noviembre del 2000, escrita y firmada por Clemente Alayo Calderón Ex Agente de Inteligencia preso en el Penal de Yanamayo, identificado con TIP-NA 306745900. La misiva lleva por título ¡Detener a Los Buitres de la Guerra!», pp. 644 (http://www.cverdad.org.pe).

COMISIÓN DE LA VERDAD Y LA RECONCILIACIÓN, «Nota de prensa 226», 2003 (http://www.cverdad.org.pe)

CONSTITUIÇÃo DA REPÚBLICA PORTUGUESA, 2 de abril de 1976 «VII Revisão Constitucional 2005» 
(www.parlamento.pt/Legislacao/Paginas/ConstituicaoRepublicaPortuguesa)

Costituzione Della Repubblica Italiana, Roma, 21 de diciembre de 1947. Senato della Repubblica. (https://www.quirinale.it)

CONGRESO DE LA REPÚBLICA, «Comisión investigadora sobre delitos económicos y financieros cometidos entre 1990 y 2001 caso: Cía. de Seguros Popular y Porvenir» 2001 , (http://www4.congreso.gob.pe/comisiones/2002/CIDEF/oscuga/InformePopular yPorvenir.pdf)

CONGRESO DE LA REPUBLICA, «Informe Final de la Comisión Investigadora de la Gestión Presidencial de Alberto Fujimori del 15 de junio del 2002». (www4.congreso.gob.pe)

CONGRESO DE LA REPUBLICA, «Primera Legislatura Ordinaria de 2011 - Tomo I - Diario de los Debates». pp. 411 - 423 (www.congreso.gob.pe)

CONGRESO DE LA REPUBLICA, «Comisiones Investigadoras Período Legislativo 2011 2016 - Departamento de Comisiones. En: Carta de Respuesta 191086 del Congresista Mauricio Mulder Bedoya de fecha 03 de diciembre de 2014». (www.congreso.gob.pe)

Congreso DE LA RepublicA, «Reglamento del Congreso de los Diputados de 10 de Febrero de 1982» (www.congreso.es)

Congreso De la RePubliCA, «Ley Constitutiva de las Cortes de 1942» (17 de julio de 1942). (www.congreso.es)

Congreso De la RePubliCA, «Constitución para la República del Perú Dictada por la Asamblea Nacional de 1919 y promulgada el 18 de Enero de 1920 Título IX Cámaras Legislativas» (http://www.leyes.congreso.gob.pe)

CONGReso DE LA RePUblicA, «Constitución política del Perú Preámbulo» (http://www4.congreso.gob.pe/grupo_parlamentario/aprista)

CONGRESO DE LA REPUBLICA, «Acusación Constitucional contra el ex presidente de la República, Alberto Fujimori por los delitos de homicidio calificado, desaparición forzada y lesiones graves, por los casos denominados "La Cantuta" y "Barrios Altos" - Denuncia Constitucional No 130» 2018, (www.congreso.gob.pe)

CONGRESO DE LA REPÚBliCA. «Comisión Investigadora de Los Casos de Corrupción de la Década 1990-2000. Área de narcotráfico y Lavado de Dinero». 21-Jul-2003. (http://www4.congreso.gob.pe/historico/ciccor/index1.html) 
Congreso de la RePúbliCA. “Comisión Permanente aprobó el levantamiento del fuero parlamentario del congresista Palomo, autorizando la privación de la libertad y el enjuiciamiento, por haber sido hallado en flagrante delito". (http://www2.congreso.gob.pe/Sicr/Prensa/heraldo.nsf/CNtitulares2/98D4ADD C33C85B3052569BA000802A2/?OpenDocument)

CONGRESO DE LA REPUBLICA, «Presidenta del Congreso de la República del 26-Jul-1999 al 19 de Nov-2000» (www.congreso.gob.pe)

CONGRESO DE LA RePUBliCA, «Acta 17ma (Extraordinaria) Sesión de Consejo Directivo del Congreso de la República, Período Anual de Sesiones 2000-2001» (www.congreso.gob.pe/diariodelosdebates)

CONGRESO DE LA REPUBliCA, «Constitución para la República del Perú - Dictada por la Asamblea Nacional de 1919 y promulgada el 18 de enero de 1920 - Augusto B. Leguía»

Congreso de la RepublicA, «Constitución Política del Perú (29 de marzo de 1933)» (http://www4.congreso.gob.pe/historico/quipu/constitu/1933.htm)

Congreso De la RePublicA, «Constitución Política del Perú (12 de Julio de 1979)» (http://www4.congreso.gob.pe/comisiones/1999/simplificacion/const/1979.htm)

CONGRESO DE LA RePUBliCA, «Declaración de Keiko Fujimorio Higushi Sesión del 17 de Setiembre de 2001»Pag. 9 (www.congreso.gob.pe)

CONGRESO DE LA REPUBLICA; «Informe de Investigación Nº 65 /2014-2015 -

Desnutrición Infantil en el Perú» Salcedo Buitrón, Sirena Diashenca (www2.congreso.gob.pe/sicr/cendocbib/con4_uibd.nsf/3C5AF80C4B3D531205 257E2E00645845/\$FILE/INFINVES65-2014.pdf

CONGRESO DE LA REPUBLICA, «Oficio NBK Bank N6171-001/AL.Reg.218. de los anexos del Informe Final de la Comisión Investigadora Sobre la Actuación y el Origen, Movimiento y Destino de los Recursos Financieros de Vladimiro Montesinos Torres y su Evidente Relación con el Ex Presidente Alberto Fujimori Fujimori» (www.congreso.gob.pe)

CONGRESO DE LA REPUBLICA, «Documentos Institucionales ordenado» (http://www.leyes.congreso.gob.pe/Documentos/constitucionales_ordenado/CO NSTT_1920)

CRONICA.COM, 2005 (www.cronica.com.mx/notas/2005/211070.html del 08/Nov/2005)

CUADRA GARcía, Ricardo A. «El Pecado de la Simonía», 2009 (https://www.elnuevodiario.com.ni/opinion/47719-pecado-simonia/) 
De la Chica Moreno, María del Rosario, «Concilio Ecuménico de Calcedonia» (http://www.expiracionjaen.net/images/PDFtextos/CONCILIOECUMNICODE

\section{CALCEDONIA)}

DATOSMACRO.COM, «Disminuye la percepción de corrupción en Perú» 2017. (http://www.datosmacro.com/estado/indice-percepcion-corrupcion/perú)

De Manjarrés, Ramón, Don Jorge Juan y Don Antonio de Ulloa: La medición del arco terrestre. La historia del platino [II]; Alicante; Biblioteca Virtual Miguel de Cervantes, 2010 (Notas de reproducción original: Edición digital a partir de Revista de Archivos, Bibliotecas y Museos: órgano del cuerpo Facultativo del

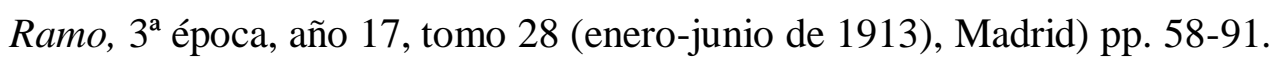

DIARIO ABC COLOR DIGITAL www.abc.com.py/edicionimpresa/internacionales/PERU-SE-MOVILIZA-PARA-EXTRADITAR-AL-EXPRESIDENTE-ALBERTO-FUJIMORI-867334.HTML

DiARIo El PAís, «Montesinos protegió el narcotráfico en Perú y Colombia. El ex asesor de Fujimori es acusado ahora por sus antiguos socios en el negocio de la coca» $\mathrm{N}^{\circ}$ 1654.

12/Nov/2000, (https://elpais.com/diario/2000/11/12/internacional/973983615_850215.html)

DIARIO El PAÍs, «La renuncia de Fujimori desde Japón provoca la dimisión de su Gobierno» 2000 (https://elpais.com/diario/2000/11/20)

DICCIONARIOS, «Persona que escribe obras dramáticas» (http://diccionarios.elmundo.es/diccionarios)

El Mundo, 2000, (www.elmundo.es)

El ESPECTADOR, 1999, (www.espectador.com)

EL UNIVERSO, 2005, (http://www.eluniverso.com/2005/11/08)

El COMERCIO, 1997, (www.elcomercio.pe)

ElCOMERCiO, «La historia de la banda presidencial con la que juró Máximo San Román», (http://elcomercio.pe/politica/gobierno/historia-banda-presidencial- que-juromaximo-san-roman)

El COMERCIO, «¿Cómo fue la fuga de Montesinos a bordo del velero Karisma?» 2013, (http://archivo.elcomercio.pe/politica/gobierno/como-fue-fuga-montesinosbordo-velero-karisma-noticia-1635429)

ESPAÑA, 2014, (http://www.libertaddigital.com/espana/2014-11-22)

EsCOBAR, Carlos, «La matanza de Cayara, Alan Garcia, Montesinos y el Ejército». (http://www.eldiariointernacional.com/spip.php?article348) 
FilosofíA.NET, «Glosario de Conceptos Filosóficos. Cuaderno de Materiales», 2016 (http://www.filosofia.net/materiales/rec/glosario.htm).

FONDO DE LAS NACIONES UNIDAS PARA LA INFANCIA - UNICEF; «Preparar a los adolescentes para la edad adulta y la ciudadanía» (www.unicef.org/spanish/sowc2011/pdfs/Preparar-a-los-adolescentes-para-la-edadadulta.pdf)

Galindo, Elola-Olaso, Fernando, «Sinopsis del artículo 76 de la Constitución Española» 2011, (www.congreso.es)

General Robles EspinozA, Rodolfo, Carta Pública de fecha 5 de mayo de 1993, (Diario Expreso del viernes 7 de mayo de 1993). Y Comisión Interamericana de Derechos Humanos - Organización de Los Estados Unidos, Caso № 11.317 Informe $N^{\circ}$ 20/99 Rodolfo Robles Espinoza e Hijos del 23 de febrero de 1999. www.cidh.org.

HODESS, Robin, «Informe global de corrupción» 2004 (www.transparency.org) HERMOZA Ríos, NiCOLÁS DE BARI, «Oficio No. 013-93-CGE del 15.04.93 dirigido al Consejo Supremo de Justicia Militar» 1993 (www.micromuseo.org.pe)

INCA GARCILASO DE LA VEGA: «Comentarios Reales», Edición, introducción y notas de Mercedes Serna Madrid, Clásicos Castalia, 2000. (http://coredise.com.pe/educacion-en-el-peru)

INSTITUTO INTERAMERICANOS DE DERECHOS HumANOS, «Ejes Transversales» (http://www.iidh.ed.cr/siii/index fl.htm)

InSTITUTO NACIONAL DE EstadísticA E INFORMÁticA «Maternal and Child Undernutrition Study Group. Maternal and child undernutrition: consequences for adult health and human capital», por Victoria C, Adair L, Fall C, Hallal P, Martorell R, Ritcher L, Sachdev H. Lancet, Series Maternal and Child Undernutrition; 2008 .

pp. $23-40$.

(www.inei.gob.pe/media/MenuRecursivo/publicaciones digitales/Est/Lib1211/p df/Libro.pdf pp. 307).

JNE, «Información político-electoral de todas las regiones, provincia y distritos del país». (http://www.infogob.com.pe/Politico/procesoelectoral)

LA CRÓNICA, 2005, (www.cronica.com.mx/notas/2005/211070.html del 08/Nov/2005)

La Gaceta «El ranking de los ex líderes más corruptos del mundo» 2011 
(https://www.lagaceta.com.ar/nota/431691/mundo/ranking-ex-lideres-mas-corruptosmundo.html)

LA NACIÓN, «¿Cómo fue la fuga de Montesinos a bordo del velero Karisma?» (http://www.lanacion.com.ar/315253-capturaron-a-montesinos-en-venezuela)

LA NACIÓN, «Investigaciones sancionan a dos oficiales por ingreso de Fujimori», 2005, (www.lanacion.cl/noticias/pais/investigaciones-sanciona-a-dos-oficiales-poringreso-fujimori/2005/11/09)

LA REPUBLICA, «En Panamá cuando estaban a punto de abordar un avión con destino a Roma Capturan a empresario», 2001, (http://larepublica.pe/21-05-2001/enpanama-cuando-estaba-punto-de-abordar-avion-con-destino-roma-capturanempresario-1)

LA RepublicA, «Crisis - Economía. Memorias del Fujishock» 2008, (http://larepublica.pe/17-08-2008/crisis-economia-memorias-del-fujishock)

LA REPUBLICA, «Exculpan a senderistas del caso Huilca», 2006, (http://larepublica.pe/0803-2006/exculpan-senderistas-de-caso-huilca)

LA REPUBLICA, «Hallan fotos que revelan como asesinaron a Mariella Barreto», (http://larepublica.pe/17-08-2010/hallan-fotos-que-revelan-como-asesinaronmariella-barreto)

LA REPUBLICA, «Matanza del Santa fue un "trabajo particular" del grupo Colina - Colina recibió 15 mil dólares para desaparecer a los nueve campesinos», 03/Ene/2003 (https://larepublica.pe/sociedad/359616-matanza-del-santa-fue-un-trabajoparticulardel-grupo-colina).

LA RePubliCA, «Agente del grupo Colina Gómez Casanova ratifica declaraciones efectuados por sus compañeros y confirma lo que le dijo Martin Rivas al periodista Umberto Jara». (larepublica.com.pe) 30/Abr/2009.

LA RePUBliCA, «Hace 18 años el General Robles denunció la Política Criminal del Gobierno de Fujimori» 2001, (http://larepublica.pe/06-05-2011/hace-18-anos-elgral-robles-denuncio-politica-criminal-de-gobierno-de-fujimori)

LA REPUBLICA, «Según los peritos, Keiko Fujimori, manejó dinero de dudoso origen», 2009, ， (http://larepublica.pe/20-05-2009/segun-los-peritos-keiko-fujimorimanejo-dinero-de-dudoso-origen)

LAS EJECUCIONES EXTRAJUdiCIALES, Universitarios de la Cantuta - Informe final de la CVR, (www.micromuseo.org.pe) 
LEDGARD, Denise, «Transcripción de la entrevista de la asesora jurídica de la embajada del Perú en Japón (entre diciembre del 2001 y marzo del 2005) en el proceso de extradición de Alberto Fujimori» 2011, (https://idl-reporteros.pe/de-cuenta-acuenta/publicado).

MiNISTERIO DE RELACIONES EXTERIORES, «Comunicado Oficial RE/ Nº 022-03 de fecha 30 de julio del 2003. Oficina de Prensa y Difusión», 2003, (https://lists.peacelink.it/latina/msg04330.html)

MIRA FERNÁNDEZ, Hernán. «Ética de la responsabilidad» http://docentesinnovadores.perueduca.

Mora DonatTo, Cecilia. «La Facultad Controladora de los Parlamentos a través de las Comisiones de Investigación. Una propuesta para México» (www.derecho.unam.mx)

MorA-DonAtTo, Cecilia «Cuestiones Constitucionales, Revista Mexicana de derecho Constitucional». Biblioteca Jurídica Virtual, (http://www.juridicas.unam.mx/publica/rev/cconst)

Montes De OCA Begazo, Emilio; «La figura del indulto es un acto presidencial de contenido jurídico y humanitario sumamente delicado, por estar en juego la libertad y la vida de la persona condenada» (http://larazon.pe/2018/02/08/elindulto-derecho-de-gracia-presidencial-con-base-constitucional/)

Montagut Contreras, Eduardo. La venta de los oficios públicos en la España del Antiguo Régimen (https://losojosdehipatia.com.es/cultura/historia/la-venta-de-los-oficiospublicos-en-la-espana-del-antiguo-regimen/)

NBK Bank Oficio Nº171-001/AL.Reg.218. de los anexos del Informe Final de la Comisión Investigadora Sobre la Actuación y el Origen, Movimiento y Destino de los Recursos Financieros de Vladimiro Montesinos Torres y su Evidente Relación con elEx Presidente Alberto Fujimori Fujimori. (www.congreso.gob.pe)

OEA, «CIDH expresa profunda preocupación y cuestiona el indulto concedido a Alberto Fujimori», 2017,(http://www.oas.org/es/cidh/prensa/comunicados/2017/218.asp)

PAEZ, Ángel, «Una Investigación de Ángel Paez» 21/Dic/2009, (http://comentariosperu.wordpress.com).

PAEZ ÁNGEL; HIDALGO MARÍA HELENA, «Operación Limpieza» Suplemento Domingo del diario La República del domingo 18 de julio del 2010, pp 06-08 (https://issuu.com/larepublica_peru/docs/domingo_180710) 
Planas, Pedro, «Centro de Capacitación y Estudios Parlamentarios» (www4.congreso.gob.pe)

Poder Judicial De la RePÚBliCA De ChILE. Prensa y Comunicaciones. 07/06/2007.

Ordenan el arresto domiciliario de Alberto Fujimori. (www.pjud.cl)

Poder Judicial de la RePúbliCA DE Chile. Prensa y Comunicaciones. Magistrados que conformaban la Segunda Sala de la Corte Suprema de Chile que resolvió la extradición: Alberto Chaigneau, Nibaldo Segura, Rubén Ballesteros, Jaime Rodríguez y Hugo Dolmestch. (www.pjud.cl)

Poder Judicial DE LA RePúBliCA DE CHILE. Prensa y Comunicaciones. Ministro Orlando Álvarez rechaza solicitud de extradición de Alberto Fujimori, en una resolución fundamentada por 122 considerandos, el Ministro Orlando Álvarez procedió a rechazar la solicitud de extradición formulada por el gobierno peruano en contra de Alberto Fujimori. Solicitudes de Extradición rechazadas: 1) Sunat Borobio. 2) Faisal Aprodev. 3) Medicinas Chinas. 4) Desvío de Fondos. 5) Decretos de Urgencia. 6) Ampliación por Desaparición Forzada. (www.pjud.cl)

Poder Judicial De la RePúbliCA DE ChILE. Prensa y Comunicaciones. 15/05/2011. La Ministra de la Corte Suprema, Rosa María Maggi Ducommun, declara improcedente ampliar la extradición del ex presidente Fujimori. Ministra desestimó la solicitud planteada, el 10 de marzo pasado, por el gobierno peruano que busca ampliar los cargos de la extradición por el delito de malversación de caudales públicos ya concedida por la Corte Suprema, en septiembre de 2007. (www.pjud.cl)

Poder Judicial DE LA RePúblicA DE ChILE. Prensa y Comunicaciones. 12/11/2012. La Corte Suprema accede a ampliar extradición de expresidente peruano Alberto Fujimori. En fallo dividido, Segunda Sala aprobó ampliar la extradición del ex Presidente del Perú Alberto Fujimori, encausado en su país por diversos delitos de violaciones a los DDHH y casos de corrupción. (www.pjud.cl)

PRESS SERVICE Abraham Lama, 19/May/1996, (http://www.ipsnoticias.net.InterAgenciadeNoticias)

ProJUSTICIA «Dirección de Imagen Institucional y Prensa del Poder Judicial: Primera Sala Mixta Transitoria del Callao sentenció a penas de entre 13 y 20 años de prisión a ocho acusados de traficar clorhidrato de cocaína en los buques BAP "Ilo" y "Matarani", entre ellos ex miembros de la Marina de Guerra, condenando a Manuel Ramos Gonzales Centeno a veinte años de prisión, y 15 años de prisión a 
Abraham Teodomiro Carrasco Rojas, Felipe Segundo Canga Luna, Cirilo Rojas Herrera, Luis Alberto Miranda Velásquez y José Luis Ormeño Huamán; otros dos acusados, Antonio Armando Agapito Huapaya y Aldo Campos Medina fueron sentenciados a 13 años de prisión». (www.projusticia.org.pe/pdf/Noti20070205.doc)

RAdio Programas DEL PeRÚ Alberto De Belaunde renunció a la bancada de PPK luego de indulto a Fujimori 24/12/2017. (rpp.pe/politica/congreso/alberto-de-belaunderenuncio-a-la-bancada-de-ppk-luego-de-indulto-a-fujimori-noticia-1096117)

RADIO PROGRAMAS DEL PERÚ ¿Qué congresistas oficialistas y funcionarios renunciaron tras el indulto a Fujimori? 03/01/2018. (rpp.pe/politica/gobierno/quienesrenunciaron-a-la-bancada-y-al-gabinete-de-ppk-noticia-1096179)

RAMÓN Cosío, José. «Las Atribuciones Legislativas del Pleno de la Suprema Corte de Justicia» (http://bibliohistorico.juridicas.unam.mx/libros)

REHBEIN, Antonio, «Apuntes del curso Historia de la Iglesia Medieval» (http://www.iglesiaehistoria.com/assets/(69)cursoiglesiamedievaljorgesilvaflores.pdf)

SAN MARTÍN CASTRO, César «La Extradición y La Cooperación Judicial Internacional» (https://www.oas.org/juridico/MLA/sp/per/sp_per_EXTRADICI\%C3\%93N_CO OP_JUD_INTE.pdf)

SWISSINFO.CH Declaraciones del Gobierno Suizo del 02-Nov-2000

(https://www.swissinfo.ch/spa/per\%C3\%BA-investiga-a-montesinos-porlavado-de-dinero)

Terrones Negrete, Eudoro, «Rasgos Biográficos de Sócrates» 2009. (www.eudorterrones.com)

VALLEJO, CRISTINA, REVISTA DigitAl FronTERAD, «Radiografía de la situación social de la población inmigrante en España». Julio 2017. (www.fronterad.com/index.php?q=bitacoras/cristinavallejo/radiografiasituacion-social-poblacion-inmigrante-en-espana)

VIANA, Israel, «Así se combatía la corrupción pública en la antigua Roma» (http://www.abc.es/archivo/20141207/abci-corrupcion-antigua-roma)

VCN506, «100 Frases Célebres de Aristóteles» (https://www.vcn506.com/2011/04/frases-celebres-de-aristoteles.html) WIKIPEDIA, La enciclopedia libre «Ágora» (https://es.wikipedia.org/wiki/Ágora) 
WIKIPEDIA, La enciclopedia libre $\quad$ «Anomia» (https://es.wikipedia.org/wiki/Anomia_(ciencias_sociales)

Zapata AvellanedA, Arturo «Artículo: el indulto por razones humanitarias a Alberto Fujimori» 2017 (http://arturozapataavellaneda.blogspot.pe/2017/12/articulo-elindulto-por-razones.html)

\section{ARTÍCULOS}

ÁlvareZ-OSSORIO FERNÁNDEZ, Carlos: «Las comisiones de investigación: ¿actos de control o instrumentos de información parlamentaria?»VI Jornadas de Derecho Parlamentario, 1995.

ArÉVAlo GutiÉRreZ, Alfonso: «Las Comisiones de investigación de las Cortes», Revista Española de Derecho Constitucional, Año 15. Núm. 43, Enero-Abril, 1995.

ArAujo, Diego et al: «Proyecto Latinoamericano para Medios de Comunicación». Memorias del Seminario Internacional. Mecanismos de Regulación de los Medios de Comunicación. Experiencias Latinoamericanas/Fundación Friedrich Ebert. En: Revista Comisión de Investigaciones Politai, 1997.

ARAGÓN, Manuel: «El control parlamentario como control político», Revista de Derecho Político, Núm. 23, 1986, pp. 9-39. En: http://revistas.uned.es/index.php/derechopolitico/article

ARÉVAlo GutiÉRREZ, Alfonso: «Las comisiones de investigación de las Cortes Generales y de las Asambleas Legislativas de las Comunidades Autónomas». Revista Española de Derecho Constitucional, núm. 43, año 15, enero-abril de 1995, pp. 113 y 114. En: El Control Político en América Latina, Chirinos Martínez, José Carlos y Rivas Gómez, Jackeline.

ArÉvalo GutiÉRrez, Alfonso: «Reflexiones sobre las Comisiones de Investigación o Encuesta Parlamentarias en el Ordenamiento Constitucional Español». Revista de las Cortes Generales, número 11. II. Notas y Dictámenes, 1987, pp. 159-192.

ArÉvalo GutiÉRreZ, Alfonso: «Las Comisiones de Investigación de las Cortes Generales y de las asambleas legislativas de las Comunidades Autónomas», En Revista Española de Derecho Constitucional, núm. 43, año 15, enero-abril 1995, pp. 124.

ARÉVAlo GutiÉRreZ, Alfonso (1994): «Las Comisiones de investigación y de encuesta», en Silva Ochoa, Juan Carlos da (coord.), Las Comisiones parlamentarias, Vitoria, 
Parlamento Vasco, págs. 361-434 En: Las Comisiones de Investigación en las Cortes Constituyentes (1977-1979). Giménez Martínez, Miguel Ángel. Revista de Estudios Políticos (nueva época) 164, Núm. 167, Madrid, enero-marzo (2015), págs. 133-164

BOTTARI, Carlo: «La investigación parlamentaria en el ordenamiento constitucional portugués». Revista Vasca de Administración Pública $\mathrm{N}^{\circ}$ 15, mayo-agosto, España, 1986. En: León Vásquez, Jorge Luis. Los Poderes y límites de las comisiones parlamentarias de investigación en el derecho constitucional peruano.

Burgos Lejonagoitia, Guillermo: «Los documentos "Secretos" de las Negociaciones del Marqués de Castelldosrius, Virrey del Perú», 2010, pp. 318. Archivo Histórico Nacional. Estado, Leg. 2.307, Revista Chronica Nova, 36, 2010, 317-338.

CASTELls, Manuel: «Comunicación y Poder», Madrid, Alianza Editorial, 2009 En: Revista Comisión de Investigaciones Politai

Daly, Jorge L. y Darío Navas Óscar; Corrupción en El Perú: Visión del Ejecutivo Peruano (QuiRoz Alfonso W: «Historia de la Corrupción en el Perú» Instituto de Estudios Peruanos). CENTRUM Católica’s Working Paper Series N²015-070007, Julio 2015.

DELla PORTA Donatella: «Partidos políticos y corrupción Reflexiones sobre el caso italiano» Nueva Sociedad, Nro. 145, Septiembre-Octubre 1996, pp. 92-109.

Domingo ORTIZ, A: «La Sociedad Americana y la Corona Española en el Siglo XVII» Madrid, 1996, pp. 166-167, En: Los Documentos Secretos de las Negociaciones del Marqués de Castelldosrius, Virrey del Perú. Burgos Lejonagoitia, Guillermo. En: Chronica Novoa, 36, 2010. Revista de Historia Moderna de la Universidad de Granada. (http://digibug.ugr.es/handle/10481/20373\#.VmFWhdIvc4w).

FERNÁNDEZ DíEZ, Estrella: «Las comisiones de investigación en el ámbito municipal» REALA. Revista de Estudios de la Administración Local y Autonómica, № 311, septiembre-diciembre 2009, pp. 89-133.

GARcíA ChÁvARri, Abraham: «La incapacidad moral como causal de vacancia presidencial en el sistema constitucional peruano» En: Revista Pensamiento Constitucional, $\mathrm{N}^{\circ} 18,2013$, pp. 390.

GARCÍA FERnÁNDEZ, Román: «El Personaje y la Imagen a propósito del Sócrates de Platón». Eikasia. Revista de Filosofía, año I, número 0, Artículo 2, julio 2005, pp. $21-22$ 
García Martínez, María Asunción: «La actividad legislativa del Parlamento como mecanismo de control político», Revista de las Cortes Generales. ํำ14, 1988, Estudios, pp. 59-94.

GIL Y GIL, José Luis: «Las Comisiones Parlamentarias de Investigación» En: Revista de Relaciones Laborales, $\mathrm{N}^{\circ}$ 8, 2000, pp. 147-162.

GiMÉNEZ MARTínEZ, Miguel Ángel: «Las Comisiones de Investigación en las Cortes Constituyentes (1977-1979)» En: Revista de Estudios Políticos (Nueva Época) N 167, Madrid, 2015, pp. 136.

GÓMEZ PAULET, Noelia Roxana: «Reflexiones sobre las gracias presidenciales a tenor de la sentencia del Tribunal Constitucional sobre el caso Jaililie». JusConstitucional, N5, Grijley, Lima, 2008, pp. 88.

GRECIET GARCÍA, Esteban: «Posición constitucional de las Comisiones de Investigación y protección de los derechos de los comparecientes». Revista parlamentaria de $\underline{\text { la }}$ Asamblea de Madrid, № 10, 2004, pp. 53.

INSTITUTO DE DEMOCRACIA Y DERECHOS HUMANOS DE LA PONTIFICA UNIVERSIDAD CATÓlica DEL Perú: «Estudios críticos sobre los delitos de corrupción de funcionarios en Perú» En: La Seguridad y sus Instituciones en el Perú a Inicios del Siglo XXI. Reformas Democráticas o Neomilitarismo. Basombrío Carlos, Rospigliosi Fernando, 2012

LindEMBERT AgUILAR, Sandra: «Análisis y comentarios a la STC Exp. № 00156-2012$\mathrm{PH} / \mathrm{TC}$ (ParteII) El debido proceso en los procedimientos de las comisiones investigadoras, le levantamiento de la inmunidad parlamentaria y ante la comisión de ética», Gaceta Constitucional, Tomo 60, Diciembre 2012, pp. 109-128

LóPEZ CALERA, Nicolás: «El Interés Público: Entre la Ideología y el Derecho». (revistaseug.ugr.es)

LuCas Murillo de la Cueva, Pablo, (1985): «Le commissioni d'inchiesta nell'ordenamento costituzionale spagnolo», en Vergottini, Giuseppe (ed.), Le inchieste delle Assemblee Parlamentari, Rimini, Maggioli, págs. 381-422 y En Giménez Martínez; Miguel Ángel. Las Comisiones de Investigación en las Cortes Constituyentes (1977-1979). Revista de Estudios Políticos (nueva época), Núm. 167, Madrid, enero-marzo (2015), págs. 133-164.

LuCas Murillo de la Cueva, Pablo, "Las comisiones de investigación de las cortes", Revista de la Facultad de Derecho de la Universidad Complutense de Madrid, núm. 10, marzo, 1986, entre otros. pp. 143-173 
Marcuello Benedicto, Juan Ignacio: «Los Reglamentos de las Cortes en la época de Isabel II», Revista de las Cortes Generales, N 4, 1985, pp. 155-196

Mogens Herman, Hansen: «El juicio de Sócrates desde el punto de vista ateniense» Universitas Philosophica 67, año 33 julio-diciembre 2016, Bogotá, Colombia ISSN 0120-5323. pp. 36

MolinA MARTíneZ, Miguel: «El Granadino Juan de Aponte y La Reforma del Perú». De: Memorial que trata de la reformación del Perú - Colección de Documentos Inéditos para la Historia de España, Aponte Figueroa, por Revista Chronica Novoa, 30, 2003-2004, 465-488. Revista de Historia Moderna de la Universidad de Granada. (http://digibug.ugr.es/handle/10481/20373\#.VmFWhdIvc4w)

Moreno CEbrían, Alfredo y SAla I VILA, Núria: «Una Aproximación a la Corrupción Política Virreinal. La Confusión entre lo Público y lo Privado en el Perú de Felipe V» En: Revista Histórica XXIX.1, 2005, pp. 69-105.

MoReno CEBríAn, Alfredo y SALA I VILA, Núria, «El premio de ser virrey. Los intereses públicos y privados del gobierno virreinal en el Perú de Felipe V», Madrid, 2004, pp. 17-150 (Una corona bien vale un virreinato: El marqués de castelldorius, primer virrey borbónico del Perú (1707-1710) pp. 30) En: Burgos Lejonagoitia, Guillermo. Los documentos "Secretos" de las Negociaciones del Marqués de Castelldosrius, Virrey del Perú. 2010. pp. 320. Revista Chronica Nova, 36, 2010, $317-338$

NAVARro Abrines, María del Carmen: «La Mina de Mercurio de Huancavelica (Perú): Entre Los Intentos de Reforma de Antonio de Ulloa y El Continuismo de Carlos de Beranger (1758-1767)» En: Scripta Nova. Revista Electrónica de Geografía y Ciencias Sociales, Universidad de Barcelona N4.1, Jun 1997.

PARDo-FigueroA Thays, Carlos y DAger Alva Joseph. «Reseña de El virrey Amat y su tiempo», Revista Historia, 2005.

Revista CARETAS: Edición Nº 1732 del 30 de mayo del 2002

Revista CARETAS, «Tantas Cuentas Pedro» 2001, (http://www.caretas.com.pe/2001)

REVISTA CARETAS, «Declaración del Fiscal Livia», 2000. (http://www.caretas.com.pe/2000/1640/articulos/barrios-altos.phtml)

REVISTA CARETAS, «Suplicios de Inteligencia» (http://caretas.pe/1460/suplicios/suplicios.htm)

Revista CARETAS, «Agente Zanatta, La Historia Completa» 1988, (http://caretas.pe/1998/1508/agente/agente.htm) 
REvista CARETAS, «Vergüenza Nacional y un Farol Presidencial» 2000, (http://www.caretas.com.pe/2000/1637/articulos/montesinos.phtml)

Revista CARetas, « Tantas Cuentas Pedro: Investigación sobre el caso Apenkai involucra al hermano del ex Presidente. Manejó el dinero de donaciones japonesas en una cuenta del exterior». Del 16 de agosto de 2001 (http://www2.caretas.pe/2001/1683/articulos/pedro.phtml)

REVISTA CARETAS, «Sabía Demasiado» 2003, pp. 82-83 (http://www.caretas.com.pe/2003/1788/articulos/chiappe.html)

REvista CARETAS, «Artículo "Mecida y Fuga". Edición No.1646. 24 de noviembre de 2000» En: Álvarez Sabogal, Julio - Autor Editor. La política exterior del Fujimorato: del autonomismo y el aislamiento económico al globalismo y el aislamiento político. 1era edición digital: Abril de 2009.

ReVISTA RAE: «Jurisprudencia. Jurisprudencia Penal \& Procesal Penal. Comentarios y anotaciones de febrero de 2009», DEFINICIÓN DE PRESCRIPCIÓN. La prescripción de la Acción Penal, pp. 409.

RODRÍGUEZ CAMPOS, Rafael: «El indulto como manifestación del derecho de gracia en la Constitución de 1993 y su tratamiento en la jurisprudencia del Tribunal Constitucional Peruano». En: Actualidad Jurídica. Número 207. Gaceta Jurídica, Lima, 2011, pp. 147.

RodríGueZ GARCíA, Nicolás: «La Necesaria Flexibilización del Concepto de Soberanía en Pro del Control Judicial de la Corrupción - La Corrupción en Mundo Globalizado», Ratio Legis, 2004.

Roncagliolo, Rafael, La democracia mediática, Lima, 2009, pp. 8-9 En: Revista Comisión de Investigaciones Politai

RojAS LÓPEZ Freddy: «Alcances y Cuestiones Generales del Procedimiento Especial de Colaboración Eficaz en el Nuevo Código Procesal Penal»Revista Derecho \& Sociedad Asociación Civil, 39, pp. 52.

SÁNCHEZ SÁNCHEZ, Javier. Comisión de investigación. Eunomía. Revista en Cultura de la Legalidad No 4, marzo - agosto 2013, pp. 187-193.

SANTAOlalla LóPEZ, Fernando: «El Parlamento y sus instrumentos de información (preguntas, interpelaciones y Comisiones de Investigación)» Edersa, Madrid, 1982 
SÁENZ-Rico Urbina, A., «Las acusaciones contra el virrey del Perú, marqués de Castelldosrius y sus "noticias reservadas" (Febrero 1709)», Boletínamericanista, XX, 1978, pp. 119. Revista Chronica Nova, 36, 2010, 317-338.

SANZ TAPIA, Ángel. «Aproximación al beneficio de cargos políticos americanos en la primera mitad del siglo XVIII». Revista Complutense de Historia de América, 1998, No 24 , pp. 147-176.

SEIJO Cristina y Villalobos Karina: «La ética social y la dignificación de la vida humana: Un alcance epistémico en la sociedad» En: Revista Clío América. Universidad de Málaga. España. Año 5 No. 9, Enero - Junio 2011, pp. 99 - 111.

\section{BOLETÍNES}

- Boletín Oficial del Estado núm. 256, de 18 de octubre de 1977, páginas 23487 a 23497.

- Boletín Oficial de las Cortes, núm. 44, de 5 de enero de 1978, páginas 669 a 724.

- Boletín Oficial de las Cortes, de 17 de abril de 1978, núm. 82, páginas 1519 a 1646. Ponencia Constitucional.

- Boletín Oficial de las Cortes, de 6 de octubre de 1978, núm. 157, páginas 3415 a 3527

- Boletín Oficial de las Cortes, de 13 de octubre de 1978, núm. 161, páginas 3559 a 3577.

- Boletín Oficial de las Cortes Generales, de 5 de marzo de 1982, núm. 55, páginas 5765 a 5769.

- Boletín Oficial del Estado - BOE núm. 305, de 21 de diciembre de 1984. pp. 15/19. Sentencia 110/1984, de 26 de noviembre.

- Boletín Oficial de las Cortes Generales, de 9 de mayo de 1994, núm. 119, páginas 1 a 36.

- Boletín Oficial del Estado núm. 298, de 14 de diciembre de 1999, páginas 43088/43099. Ley Orgánica 15/1999, de 13 de diciembre, de Protección de Datos de Carácter Personal. 
- Boletín Oficial del Estado núm. 302, de 18 de diciembre de 2003, páginas $44987 / 45065$

- Boletín Oficial del Estado núm. 156, de 27 de junio de 2014, pp. 49412/49549. Ley 10/2014, de 26 de junio, de ordenación, supervisión y solvencia de entidades de crédito.

- Boletín Oficial del Estado núm. 255, de 24 de octubre de 2015, pp. 100356/100541. Real Decreto Legislativo 4/2015, de 23 de octubre, texto refundido de la Ley del Mercado de Valores.

- Boletín Oficial del Estado núm. 261, de 31 de octubre de 2015, pp. 103291/103519 - REAL DeCRETo Legislativo 8/2015, DE 30 DE OCTUBRE, TEXTO REFUNDIDO DE LA LEY GENERAL DE LA SEGURIDAD SOCIAL.

\section{CONVENIOS}

- Convenio Específico de Cooperación Interinstitucional entre el Gobierno Regional de Junín y la Empresa de Servicios Industriales de la Marina S.A. - SIMA PERÚ No 45-2011-GGR/GRJ

- Convenio Marco Cooperación entre el Gobierno Regional Junín y la Empresa de Servicios Industriales de la Marina S.A. - SIMA PERÚ N 004-2011-REGIÓN JUNÍN/PR SP-2011, el 29 de marzo de 2011.

\section{CONGRESO DE LA REPÚBLICA DEL PERÚ}

- Congreso de la República de Perú. Informe Final Comisión Investigadora Waisman.

- Congreso de la República de Perú. 17/06/2015. Acta de la Vigésima Sesión Ordinaria del 17/Jun/2015 de la Comisión Investigadora Martín Antonio Belaunde Lossio. En: congreso.gob.pe

- Congreso de la República de Perú. 25/07/2003. Comisión Investigadora Encargada de Implementar las Conclusiones y Recomendaciones de las Investigaciones sobre los Actos de Corrupción cometidos entre 1990-2000.

- Congreso de la República del Perú. 1993. Edición Oficial del Congreso de la República. 
- Congreso de la República del Perú.16/07/2001. Oficio No 82-62-2001-6JPEL del 16 de julio del 2001 mediante la cual remite al Congreso de la República las copias de la declaración instructiva de Vladimiro Montesinos Torres tomadas en la Base Naval del Callao, lugar donde se encuentra recluido el acusado.

\section{DECLARACIONES}

- Declaración Testimonial de Clemente 26/07/2001. Alayo Calderón tomada el 26 de julio del 2001, pp. 5992. Expediente del caso Barrios Altos. 5to. Juzgado Anticorrupción.

- Declaraciones de la Fiscal de la Nación Nelly Calderón

- Declaraciones hechas por el narcotraficante Demetrio Chávez Peñaherrera efectuadas el 17/08/1996 en un proceso penal

- Declaración de Néstor Javier Corrochano Patrón

- Declaraciones testimoniales de Ubillús 7, Pérez Del Águila, y Fujimori Fujimori

- Declaraciones testimoniales de Cornejo Valdivia, Fifzcarrald Guerrero y Burns O'Hara

- Declaraciones, testimonio y hechos descritos en la Sentencia de fecha 11/12/2007. Expediente $\mathrm{N}^{\circ} 13-2003$

\section{DECRETO LEGISLATIVO}

- DECRETO LEGiSlativo Nº 635, Código Penal Peruano

- DECRETO LEGISLATIVO 29/05/1994, que regula la obligación de comunicación de determinados datos a requerimiento de las comisiones parlamentarias de investigación.

- DECRETO LEGISLATIVO N²95. Código Civil del Perú.

\section{EXPEDIENTES}

- Expediente 424-83 Consejo Supremo de Justicia Militar - Proceso seguido con Vladimiro Montesinos Torres ante la justicia militar por Traición a la Patria, ventilado en secreto entre los años 1983-1985. 
- Expediente No 00235-2017-JUS/CGP - Expediente Administrativo de solicitud de Indulto de Alberto Fujmori Fujimori

\section{INFORMES}

- Informe $\mathrm{N}^{\circ}$ 20/99 dictamen Robles Espinoza e Hijos del 23 de febrero de 1999, Caso $\mathrm{N}^{\circ}$ 11.317; Corte Interamericana de Derechos Humanos.

- Informe Final de la Comisión Investigadora Martín Belaunde Lossio, 31 de agosto 2015.

- Informe Final de la Comisión Investigadora Sobre la situación, el origen y destino del dinero de Vladimiro Montesinos Torres y su evidente relación con el ex presidente Alberto Fujimori Fujimori. Junio 2002.

- Informe Final de la Comisión Investigadora por el uso de los gastos atendidos por el Sector Defensa con financiamiento de recursos provenientes de la privatización. Junio 2002.

- Informe Final de la Comisión Investigadora de los hechos relacionados con las denuncias por la supuesta existencia de una red de interceptaciones telefónicas. Mayo 2009.

- Informe Final de la Comisión Investigadora de los Casos de Corrupción de la Década 1990-2000 Área de Narcotráfico y Lavado de Dinero. Julio 2003.

- Informe Final de la Comisión Investigadora de Delitos Económicos y Financieros Cometidos entre 1990-2001. Junio 2002.

- Informe Final de la Comisión Investigadora de la Gestión Presidencial de Alberto Fujimori. 15 de junio 2002.

- Informe Final de la Comisión Investigadora sobre la influencia irregular para controlar el Poder Judicial y el Ministerio Público. 25 de Julio 2003.

- Informe Final de la Comisión Investigadora Servicio de Inteligencia Nacional y las redes internas con Instituciones Públicas y adquisiciones de las Fuerzas Armadas y Policiales. 21 de Julio 2003.

\section{LEYES}

Perú 
- Ley $\mathrm{N}^{\circ}$ 28024, Ley que regula la gestión de intereses en la Administración Pública, promulgada con el objeto de asegurar la transparencia en las acciones del Estado.

- Ley $\mathrm{N}^{\circ} 27362$ - Ley que establece beneficios por colaboración eficaz en el ámbito de la criminalidad organizada

- Ley $\mathrm{N}^{\circ} 26656$ - Ley que Establece modalidades y plazos para las autorizaciones de salida del país del Presidente de la República.

- Ley $\mathrm{N}^{\circ} 24710$ - La persona procesada, acusada o condenada como autor, cómplice o encubridor de algún delito que se encuentre en otro estado, puede ser extraditada

- Ley N² 28760 - Ley que modifica los artículos 147, 152 y 200 del Código Penal y el artículo 136 del Código de Procedimientos Penales y señala las normas a las que se sujetarán los beneficios penitenciarios en el caso de sentenciados por delito de secuestro.

- Ley $\mathrm{N}^{\circ} 27378$ - Ley que establece beneficios por colaboración eficaz en el ámbito de la criminalidad organizada.

\section{España}

- Ley 9/1968. de 5 de abril sobre Secretos Oficiales Publicada en el Boletín Oficial del Estado, núm. 84, del 06 de abril de 1968 pp. 5197/5199

- Real Decreto Ley 5/1994, 29 de abril, Regula la Obligación de Comunicación de Determinados Datos a Requerimiento de las Comisiones parlamentarias de Investigación, publicada en el Boletín Oficial del Estado, núm. 103, de 30 de abril de 1994, página 13428.

- Ley Orgánica 10/1995 del Código Penal español artículo 502.1

- Ley 15/1999. de 13 de diciembre, de Protección de Datos de Carácter Personal publicada en el Boletín Oficial del Estado, núm. 298, del 14 de diciembre de 1999 pp. 43088/43099.

- Ley 58/2003. de 17 de diciembre, General Tributaria publicada en el Boletín Oficial del Estado, núm. 302, del 18 de diciembre de 2003 pp. 44987/45065.

- Ley Orgánica 15/2003 del Código Penal español

- Real Decreto Legislativo 8/2015, 30 de octubre, Texto Refundido de la Ley General de la Seguridad Social publicada en el Boletín Oficial del Estado núm. 261, de 31 de octubre de 2015, pp. 103291/103519 


\section{REGLAMENTOS}

- Reglamento sobre Secretos Oficiales Decreto 242/1969 del 5 de febrero publicada en el Boletín Oficial del Estado núm. 47, de 24 de febrero de 1969, pp. 2839/2842.

- Reglamento Provisional del Senado Español, de 18 de octubre de 1977.

- Reglamento del Congreso de los Diputados (España) de 24 de febrero de 1982 Boletín Oficial de las Cortes Generales; núm. 55, de 5 de marzo de 1982, pp. 5765 a 5769.

- Reglamento del Senado (España) del 03 de mayo de 1994 - Boletín Oficial de las Cortes Generales; Senado V Legislatura, núm. 119, de 9 de mayo de 1994, pp. 1 a 36.

- Reglamento del Congreso de la República del Perú del 13 de junio de 1995. Primera Edición. Oficialía Mayor. 2015.

- Reglamento Parlamento Europeo 8 ${ }^{\text {a }}$ Legislatura julio 2014.

- Reglamento de Extranjería de Chile. Decreto Supremo No 597

\section{RESOLUCIONES}

- Resolución Administrativa de Sala Plena de la Corte Suprema de Justicia de la República - RA Nº 002-2010-SP-CS-PJ de fecha 22 de enero de 2010

- Real Decreto 242/1969, 20 de febrero publicada en el Boletín Oficial del Estado núm. 47, de 24 de febrero de 1969, pp. 2839/2842

- Resolución Legislativa $\mathrm{N}^{\circ}$ 008-2000-CR del22/Nov/2000

- Resolución Legislativa Nº10-2000-CR del22/Nov/2000

- Resolución Legislativa $\mathrm{N}^{\circ} 27355$ emitida por la Comisión Permanente del Congreso que Autoriza al Presidente de la República a realizar viajes al exterior.

- Resolución Ministerial N 0162-2010-JUS - Reglamento Interno de la Comisión de Gracias Presidenciales.

- Resolución Suprema No 281-2017-JUS del 24 de diciembre de 2017 - Conceden indulto y derecho de gracia por razones humanitarias a interno del Establecimiento Penitenciario Barbadillo. 


\section{SENTENCIAS}

- Sentencia del Juzgado Especializado en lo Constitucional - Expediente $\mathrm{N}^{\circ} 15$ 19/09/2013 Expediente $\mathrm{N}^{\circ}$ 014923-2013-1801-JR-CI-05 5to Juzgado Especializado en lo Constitucional

- Sentencia del Juzgado Penal Expediente $N^{\circ}$ 23304-2013 3er Juzgado Penal de Lima de fecha 7 de enero de 2014. Demanda de Habeas Corpus Caso Alejandro Toledo.

- Corte Superior de Justicia de Lima. Primera Sala Civil Expediente $N^{\circ} 14923$ 2013-0-1801-JR-CI-05 Resolución N catorce de fecha 27 de diciembre de 2013 - Caso Alán García Pérez (Debido Proceso en sede Parlamentaria).

\section{SENTENCIA DE LA CORTE SUPREMA}

- Corte Suprema de Justicia de la República 09/2003. El informe se incorporó en el expediente judicial No $09-2003$, de la Primera Sala Penal Especial de la Corte Suprema del Perú.

- Corte Suprema de Justicia de la República 06/2001 Sala Penal Especial Nº6-2001. Declaración Luis Alberto Emilio Kouri Bumachar

- Corte Suprema de Justicia de la República. Sala Penal Especial - 1 - Expediente No AV-23-2001 se fecha 20/07/2009

- Corte Suprema de Justicia de la República. Sala Penal Especial. Expediente $N^{\circ}$ RN.14-2001 de fecha 16/05/2003

- Corte Suprema de Justicia de la República. Sala Penal Especial. Expediente $N^{\circ}$ AV.09-2001 de fecha 23/01/2003

- Corte Suprema de Justicia de la República. Vocalía Suprema de Instrucción. Expediente $\mathrm{N}^{\circ}$ 13-2002-Av de fecha 27 de junio de 2006. Condenada a 6 años de Pena Privativa de Libertad como autora del delito contra la Tranquilidad Pública. Asociación Ilícita para Delinquir. Corrupción de Funcionarios. Cohecho Pasivo de Magistrados en agravio del Estado.

- Corte Suprema del Colegiado B de la Sala Penal Nacional emitido el 09 de febrero de 2018 y recaído en el Expediente N00649- 2011-0 - 5001-JR-PE-03 SS. 


\section{SENTENCIAS TRIBUNAL CONSTITUCIONAL}

\section{Perú}

- $\quad$ STC Expediente No 3966-2004-HC/TC - 03/Mar/2005 Los Procesos Penales, Tomo 6, Barcelona. Ed. Bosh, 2000, p. 834 En: Sentencia del Tribunal Constitucional

- $\quad$ STC Expediente $N^{\circ}$ 00156-2012-PHC de fecha 8 de agosto de 2012. Caso Tineo Cabrera

- $\quad$ STC Expediente No 00006-2003-AI-TC del 01 de diciembre de 2003.

- STC Expediente 13-2003 11/12/2007. Fundamentos de hecho. Información probatoria

- $\quad$ STC Expediente $\mathrm{N}^{\circ} \mathrm{AV}-14-2003$

- STC 11/12/2007. Exp. 13-2003 confirmada por la Segunda Sala Penal de la Corte Suprema de Justicia AV. 13-2003 del 10 de abril de 2008. Resolución N 17-2008

- STC Expediente No AV-19-2001. Sala Penal Especial de la Corte Suprema de Justicia. 25 personas: (Caso Barrios Altos), (Caso La Cantuta) y (Caso Sótanos SIE) agraviados: Gustavo Andrés Gorriti Ellenbogen y Samuel Edward Dyer Ampudia.

- $\quad$ STC Expediente $N^{\circ}$ 63-09 de la Cuarta Sala Penal Liquidadora de la Corte Superior de Justicia de Lima de fecha 08/01/2015

- $\quad$ STC N ${ }^{\circ} 00156-2012-\mathrm{PHC}$

- $\quad$ STC (Resolución N 15) del 19/09/2013. Expediente Nº14923-2013-1801-JR-CI05 del 5 to Juzgado Especializado en lo Constitucional.

- STC Exp. $N^{\circ}$ 0090-2004-AA/TC de fecha 05/07/2004. Revista española de Derecho Administrativo, disco compacto, Madrid, Civitas Ediciones, Revista No 008, enero marzo de 1976] plantee que la noción interés público se entienda como expresiones del valor público que en sí mismo tienen ciertas cosas; o bien como expresión de aquello que únicamente interesa al público.

- STC. Fundamento 2do del Exp. № 1805-2005-HC/TC. Tribunal Constitucional del Perú. 
- STC. 12/02/2007. Pleno Jurisdiccional 006-2006-PC/TC Sentencia del Pleno Jurisdiccional del Tribunal Constitucional del 12-Feb-2007 Proceso Competencial Poder Ejecutivo (Demandante) C. Poder Judicial (Demandado).

\section{España}

- Sentencia 110/1984, de 26 de noviembre, pp. 15-19. Boletín Oficial del Estado - BOE núm. 305, de 21 de diciembre de 1984.

- Sentencia 227/2004, de 29 de noviembre - Boletín Oficial del Estado - BOE núm. 3, de 04 de enero de 2005.

\section{SENTENCIA DE LA CORTE INTERAMERICANA DE DERECHOS HUMANOS}

- SCIDH 14/03/2001. Sentencia de la Corte Interamericana de Derechos Humanos. Caso Barrios Altos Vs. Perú

- SCIDH. 17/04/2015. Sentencia de la Corte Interamericana de Derechos Humanos en el caso Cruz Sánchez y Otros Vs. Perú. Resumen Oficial Emitido por la Corte Interamericana de la Sentencia En: http://www.corteidh.or.cr

\section{Otros}

- Acta de la Segunda Legislatura Ordinaria del Período Anual de Sesiones 2001-2002 - 6 ${ }^{a}$ Sesión Extraordinaria, celebrada el miércoles 3 de abril de 2002 y presidida por los Congresistas Carlos Ferrero Costa y Luis Ibérico Núñez

- Copia del documento remitido por la Secretaria General de la Presidencia de la República - Palacio de Gobierno de fecha 21/Nov/2000 adjuntando el fax con la renuncia del Alberto Fujimori Fujimori

- CNDH. 04/2003. "Fujimori extraditable". Diez años dictadura, corrupción y violaciones a los derechos humanos. Coordinadora Nacional de Derechos Humanos.

- CSJC. Dictamen Pericial del Equipo Peruano de Antropología Forense, (EPAF). José Pablo Baraybar, ante la tercera sala penal de la Corte Superior de Justicia del Callao.

- Escrito Abierto. 20/08/2001, del ex Primer Secretario de la Embajada del Japón en Lima, Hidetaka Ogura, en escrito abierto cursado a las "autoridades del Poder Judicial de la República del Perú" 
- Informe Social Nº 01-2017-INPE/18-239-S.S., de fecha 04 de diciembre de 2017 En: Resolución Suprema N²81-2017-JUS del 24 de diciembre de 2017

- Oficio $\mathrm{N}^{\circ}$ 058-2017-INPE/18-239-salud, de fecha 18 de diciembre de 2017 En: Resolución Suprema No 281-2017-JUS del 24 de diciembre de 2017

- Oficio NBK Bank Nº6171-001/AL.Reg.218. de los anexos del Informe Final de la Comisión Investigadora Sobre la Actuación y el Origen, Movimiento y Destino de los Recursos Financieros de Vladimiro Montesinos Torres y su Evidente Relación con el Ex Presidente Alberto Fujimori Fujimori. En: www.congreso.gob.pe

- U.S. Embassy (Dion) a S.S., Lima, 19 de junio de 1990, Nº9127, copia desclasificada del USDS, en PDC, box 36, file SIN. En: Quiroz Alfonso W., Historia de la Corrupción en el Perú, Instituto de Estudios Peruanos, 2013, pp.360

- Yon Javier Pérez Paredes. 05/2013. Tesis Medios de comunicación. 